\title{
Microstructural Regulation, Oxidation Resistance and Mechanical Properties of Cf/SiC/SiHfBOC Composites Prepared By Chemical Vapor Infiltration With Precursor Infiltration Pyrolysis
}

\author{
Yang LYU \\ Harbin Institute of Technology \\ Baihe DU \\ Harbin Institute of Technology \\ Guiqing CHEN \\ Harbin Institute of Technology \\ Guangdong ZHAO \\ Heilongjiang University

\section{Yuan CHENG} \\ Harbin Institute of Technology \\ Shanbao ZHOU \\ Harbin Institute of Technology \\ Qingrong LV \\ Anhui University \\ Xinghong ZHANG \\ Harbin Institute of Technology \\ W.B. Han ( $\nabla$ wbhan@hit.edu.cn ) \\ Harbin Institute of Technology https://orcid.org/0000-0002-2931-6434
}

\section{Research Article}

Keywords: $\mathrm{Cf} / \mathrm{SiC} / \mathrm{SiHfBOC}$ composites, Precursor infiltration pyrolysis method, Mechanical properties, High-temperature oxidation resistance

Posted Date: April 14th, 2021

DOI: https://doi.org/10.21203/rs.3.rs-416204/v1

License: (c) (1) This work is licensed under a Creative Commons Attribution 4.0 International License.

Read Full License 
Version of Record: A version of this preprint was published at Journal of Advanced Ceramics on October 27th, 2021. See the published version at https://doi.org/10.1007/s40145-021-0521-y. 


\title{
Microstructural Regulation, Oxidation Resistance and Mechanical Properties of $\mathrm{C}_{\mathrm{f}} / \mathrm{SiC} / \mathrm{SiHfBOC}$ Composites prepared by chemical vapor infiltration with precursor infiltration pyrolysis
}

\author{
Yang $\mathrm{LYU}^{a}$, Baihe $\mathrm{DU}^{a}$, Guiqing $\mathrm{CHEN}^{a}$, Guangdong $\mathrm{ZHAO}^{b}$, Yuan $\mathrm{CHENG}^{a}$, Shanbao ZHOU ${ }^{a} *$, \\ Qingrong $\mathrm{LV}^{c}$, Xinghong $\mathrm{ZHANG}^{a}$, Wenbo $\mathrm{HAN}^{a}$,* \\ ${ }^{a}$ National Key Laboratory of Science and Technology on Advanced Composites in Special \\ Environments, and Center for Composite Materials and structures, Harbin Institute of Technology, \\ Harbin 150080, PR China \\ ${ }^{b}$ School of Chemistry and Materials Science, Heilongjiang University, Harbin 150080, PR China \\ ${ }^{c}$ School of Physics and Material Science, Anhui University, Hefei 230601, PR China
}

\begin{abstract}
:
To further improve the oxidation resistance of PDC (Polymer Derived Ceramic) composites in harsh environments, $\mathrm{C}_{\mathrm{f}} / \mathrm{SiC} / \mathrm{SiHfBOC}$ composites were prepared by $\mathrm{CVI}$ (Chemical Vapor Infiltration) and PIP (Precursor Impregnation Pyrolysis) methods. The weight retention change, mechanical properties, and microstructure of $\mathrm{C}_{\mathrm{f}} / \mathrm{SiC} / \mathrm{SiHfBOC}$ before and after oxidation in air were studied in detail. Microscopic analysis showed that only the interface between the ceramic and fibers were oxidized to some extent and hafnium had been enriched on the composite surface, after oxidation at different oxidation environments. After $\mathrm{C}_{\mathrm{f}} / \mathrm{SiC} / \mathrm{SiHfBOC}$ composites oxidized at $1500{ }^{\circ} \mathrm{C}$ for $60 \mathrm{~min}$, it was mainly determined by the $\mathrm{HfO}_{2}$ and $\mathrm{HfSiO}_{4}$ phase. Moreover, the weight retention ratio and compressive strength of the $\mathrm{C}_{\mathrm{f}} / \mathrm{SiC} / \mathrm{SiHfBOC}$ composites are $83.97 \%$ and $23.88 \pm 3.11 \mathrm{MPa}$, respectively. It indicates that the $\mathrm{C}_{\mathrm{f}} / \mathrm{SiC} / \mathrm{SiHfBOC}$ composites can be used for a long time in the oxidation environment at $1500{ }^{\circ} \mathrm{C}$.
\end{abstract}

Keywords: $\mathrm{C}_{\mathrm{f}} / \mathrm{SiC} / \mathrm{SiHfBOC}$ composites, Precursor infiltration pyrolysis method, Mechanical properties, High-temperature oxidation resistance

*Corresponding author. E-mail address: wbhan@ @it.edu.cn 


\section{Introduction}

With the emergence of hypersonic spacecraft, the requirements of thermal protection materials such as lightweight, strengthening-toughening, and oxidation resistance of thermal protection materials are increasing in the combustion chamber and tail nozzle of aerospace vehicles [1-3]. The thermal protection materials represented by ceramic thermal insulation tiles are difficult to meet the requirements of increasing the service environment temperature of hypersonic spacecraft [4-7].

In addition, ceramic matrix composites have attracted much attention due to their excellent thermal stability and high compressive strength [8]. However, the intrinsic brittleness and poor thermal shock resistance of ultra-high temperature seriously restrict the wide application of ceramic thermal protection materials $[9,10]$. The high-performance silicon-based precursor ceramics have excellent thermodynamic stability. SiOC based precursor ceramics have been applied in the hot end components of aerospace vehicles. However, the strong carbothermal reduction ccurs in the environment above $1300{ }^{\circ} \mathrm{C}$, which seriously restricts the development of silicon-based precursor ceramics. It is found that the high-temperature stability of SiOC ceramics can be effectively improved by doping boron, nitrogen, zirconium, hafnium, and other elements. At present, a variety of precursor ceramics have been synthesized, such as SiBOC [11]、SiZrOC [12]、SiHfOC [12] SiAlOC [13]、SiBCN [14]、SiHfBOC [3]、SiBCNZr [14], etc.

Continuous carbon fiber (or carbon fiber perform) reinforced ceramic matrix composites have excellent properties, such as low density [15], high toughness [16], high strength, and high reusability [17], especially the toughening property [18], which helps to solve the inherent brittleness of ceramic materials [19]. It not only improves the thermal shock resistance of ceramic materials but also maintains the inherent high-temperature stability and low thermal expansion coefficient of ceramic materials [8]. Therefore, continuous carbon fiber reinforced ceramic matrix composites has been widely studied in recent years.

However, due to the low reaction activity of carbon fiber and the damage of carbon fiber in a hightemperature oxidation environment, the interface bonding performance between continuous fiberreinforced phase and the ceramic matrix will be reduced, and the excellent characteristics of 
continuous carbon fiber cannot be brought into full play. The coating will reduce the area of carbon fiber exposed to oxygen atmosphere, thus improving the oxidation resistance of the composites Therefore, Chemical vapor deposition (CVD), chemical vapor infiltration (CVI), and hydrothermal methods can be used to prepare coatings on carbon fiber surface $[1,17,20]$. The types of coatings can include C coating [21], BN coating [22], SiC coating [23], etc. These coatings can not only change the surface roughness of carbon fiber but also improve the interface bonding performance between ceramic matrix and carbon fiber reinforcement. In the process of ceramic pyrolysis, the coating can also protect carbon fibers by inhibiting the surface damage of carbon fiber.

The precursor solution of SiHfBOC was prepared in the previous work. Therefore, in this paper, $\mathrm{SiC}$ coating was prepared on the surface of carbon fiber by CVI, and then SiHfBOC precursor sol was ultrasonically impregnated into the framework of carbon fiber preform coated with $\mathrm{SiC}$ coating by PIP. After solvothermal reaction and high-temperature pyrolysis, $\mathrm{C}_{\mathrm{f}} / \mathrm{SiC} / \mathrm{SiHfBOC}$ ceramic matrix composites were prepared. Their micromorphology and phase evolution were analyzed. Additionally, the strengthening-toughening mechanism and oxidation resistance of $\mathrm{C}_{\mathrm{f}} / \mathrm{SiC} / \mathrm{SiHfBOC}$ ceramic matrix composites were also evaluated.

\section{Experimental}

\subsection{Materials}

The commercially available methyltriethoxysilane (MTES, $\mathrm{CH}_{3} \mathrm{Si}\left(\mathrm{OCH}_{2} \mathrm{CH}_{3}\right)_{3}, 99 \%$ purity, purchased from Aladdin Co. Ltd., Shanghai, China), boric acid $\left(\mathrm{B}(\mathrm{OH})_{3} 98 \%\right.$ purity, purchased from Harbin Chemical Reagent Factory Co. Ltd., Harbin, China), tetrachloride hafnium $\left(\mathrm{HfCl}_{4}, 99.5 \%\right.$ purity, purchased from Aladdin Co. Ltd., Shanghai, China), T700 PAN-based carbon fibers $\left(\mathrm{C}_{\mathrm{f}}\right.$ preform, purchased from Yixing Tianniao High Technology Co. Ltd., Jiangsu, China) and Methyl trichlorosilane and Hydrogen (MTS and $\mathrm{CH}_{3} \mathrm{SiCl}_{3} \mathrm{H}_{2}, 99.99 \%$ purity, purchased from Institute of metal research, Chinese Academy of Sciences, Shenyang, China) were used here as received.

\subsection{Materials synthesis and processing}

In our previous study, the preparation method of the SiHfBOC precursor solution was reported [3]. At the same time, SiC coating was prepared on the surface of carbon fiber by CVI method to protect the carbon fiber and improve its bonding strength with the SiHfBOC precursor solution. After 
degumming, the $\mathrm{C}_{\mathrm{f}}$ preform $(64 \mathrm{~mm} \times 64 \mathrm{~mm} \times 25 \mathrm{~mm})$ was placed in chemical vapor infiltration (CVI) equipment. The MTS mass fraction of the precursor gas mixture was $40 \mathrm{wt} . \%$, the gas flow rate was $40 \mathrm{ml} / \mathrm{min}$, and the deposition temperature was $1000{ }^{\circ} \mathrm{C}$. Afterward, the SiHfBOC precursor solution was ultrasonically impregnated into the $\mathrm{C}_{\mathrm{f}}$ preform coated with $\mathrm{SiC}$ coating. The precursor solution of $\mathrm{SiHfBOC}$ was impregnated into $\mathrm{SiC} / \mathrm{C}_{\mathrm{f}}$ preform by ultrasonic and then put into the reactor. After a solvothermal reaction at $120{ }^{\circ} \mathrm{C}$ for $720 \mathrm{~min}$, the sample was further pyrolyzed in a tubular furnace. Finally, $\mathrm{C}_{\mathrm{f}} / \mathrm{SiC} / \mathrm{SiHfBOC}$ composites were prepared by multiple PIP cycle times.

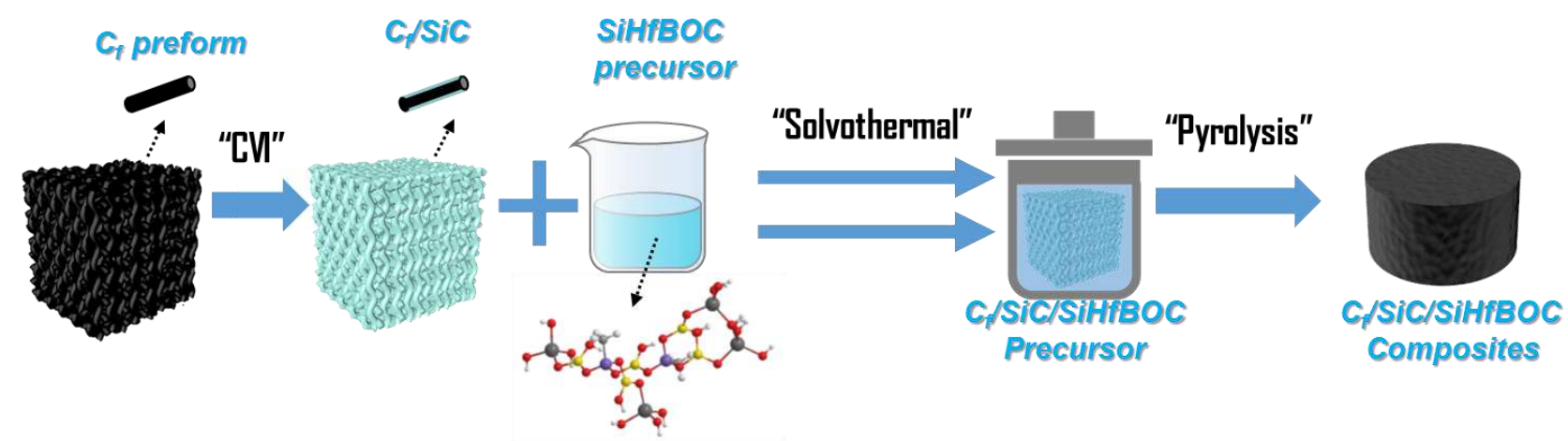

Fig. 1. Illustration of the preparation process of $\mathrm{C}_{\mathrm{f}} / \mathrm{SiC} / \mathrm{SiHfBOC}$ composites.

\subsection{Characterization}

This experiment used an X-ray diffractometer (XRD) of the type Empyrean Sharp (Panalytical, Netherlands) equipped with monochromatic Mo Ka radiation at a scan speed of $10 \%$ min in the 2theta range of $10-90^{\circ}$. It was used for crystal identification, phase identification, and quantitative analysis. It has high reception efficiency, sensitivity, and precision. The surface morphology $\mathrm{C}_{\mathrm{f}}$, $\mathrm{C}_{\mathrm{f}} / \mathrm{SiC}$, and $\mathrm{C}_{\mathrm{f}} / \mathrm{SiC} / \mathrm{SiHfBOC}$ composites were analyzed by SEM.Scanning electron microscopy (SEM) was performed on a HELIOS NanoLab 600i (FEI, USA) with energy dispersive spectroscopy (EDS). Secondary electron image resolution: $0.9 \mathrm{~nm}(15 \mathrm{kV}), 1.4 \mathrm{~nm}(1 \mathrm{kV})$, magnification: 40600000; acceleration voltage: $0.5-30 \mathrm{kV}$; ion imaging resolution: $4 \mathrm{~nm}(30 \mathrm{kV})$ Acceleration voltage: 0.5-30 kV. The density and porosity of $\mathrm{C}_{\mathrm{f}}$ preform, $\mathrm{C}_{\mathrm{f}} / \mathrm{SiC}$ preform and $\mathrm{C}_{\mathrm{f}} / \mathrm{SiC} / \mathrm{SiHfBOC}$ composites 
were measured and calculated by Archimedes drainage method. The oxidation process of the thermogravimetric analyzer was simulated by a muffle furnace.

\subsection{Static oxidation tests and mechanics performance testing}

The static oxidation resistance test was carried out in a muffle furnace. The $\mathrm{C}_{\mathrm{f}} / \mathrm{SiC} / \mathrm{SiHfBOC}$ composites with the dimension of $10 \mathrm{~mm} \times 10 \mathrm{~mm} \times 10 \mathrm{~mm}$ were placed in a corundum crucible, and then the crucible was placed in a muffle furnace at the target temperature. After oxidation at the set oxidation temperature for a period, the oxidized samples were taken out and cooled naturally at room temperature. The weight of samples before and after the oxidation test was recorded by analytical balance. The calculation formula of oxidation weight retention ratio (W\%) was shown in Eqs (1):

$$
W \%=\frac{m_{0}-m_{1}}{m_{0}} \times 100 \%
$$

Where $W \%$ is oxidation weight retention ratio of sample; $m_{0}, m_{1}$ is the weight of the sample before and after oxidation, respectively. The oxidation weight retention ratio is the average of three samples. Finally, the static oxidation resistance of $\mathrm{C}_{\mathrm{f}} / \mathrm{SiC} / \mathrm{SiHfBOC}$ composites was analyzed according to formula (1) and SEM, EDS, and XRD results.

The flexural strength and compressive strength of $\mathrm{C}_{\mathrm{f}} / \mathrm{SiC} / \mathrm{SiHfBOC}$ composites were tested by three-point bending using DCS-250kN electronic universal material testing machine. The prepared samples of flexural strength were processed into $3 \mathrm{~mm} \times 4 \mathrm{~mm} \times 22 \mathrm{~mm}$, and the samples were ground and polished to eliminate the error. The effective span was set at $16 \mathrm{~mm}$ and the loading ratio of indenter was set at $0.5 \mathrm{~mm} / \mathrm{min}$. The loading direction was divided into $\mathrm{x} / \mathrm{y}$ direction and $\mathrm{z}$ direction, which were perpendicular to and parallel to the carbon fiber layer respectively. The samples of compressive strength were processed into $10 \mathrm{~mm} \times 10 \mathrm{~mm} \times 10 \mathrm{~mm}$. The loading ratio of the indenter and loading direction were the same as above. The calculation formula of flexural strength $\left(\sigma_{f}\right)$ and compressive strength $\left(\sigma_{c}\right)$ was shown in formula (2) and (3), respectively [24]:

$$
\begin{gathered}
\sigma_{f}=\frac{3 P_{f} L}{2 h^{2} W} \\
\sigma_{c}=\frac{P_{c}}{h W}
\end{gathered}
$$


Where $P_{f}$ and $P_{c}$ are maximum loads during the test; $L$ is span; $h$ is sample height; $W$ is sample width; $\sigma_{f}, \sigma_{c}$ are flexural and compressive strength, respectively. The flexural and compressive strength is the average of three samples. Then the strength retention ratio was calculated by the ratio of compressive strength after and before the static oxidation test. And the strengthening and toughening mechanism of $\mathrm{C}_{\mathrm{f}} / \mathrm{SiC} / \mathrm{SiHfBOC}$ composites were analyzed based on the fracture images observed by SEM.

\section{Results and discussion}

\subsection{Microstructure regulation of $\mathrm{C}_{\mathrm{f}} / \mathrm{SiC} / \mathrm{SiHfBOC}$ composites}

The XRD patterns and microstructure of $\mathrm{C}_{\mathrm{f}}$ and $\mathrm{SiC} / \mathrm{C}_{\mathrm{f}}$ are shown in Fig. 2. The amorphous diffraction peak of $\mathrm{C}$ was detected near $2 \theta=25.5^{\circ}$ in untreated $\mathrm{C}_{\mathrm{f}}$ samples. In addition to the amorphous diffraction peaks of $\mathrm{C}$, the diffraction peaks of $\mathrm{SiC}$ at $35.6^{\circ}, 60.1^{\circ}$, and $71.9^{\circ}$ were also found in the XRD patterns of $\mathrm{SiC} / \mathrm{C}_{\mathrm{f}}$ samples $[23,25,26]$, which further indicated the existence of $\mathrm{SiC}$ coating. It can be seen from Figs. 2 (b)-2 (d) that the carbon fiber bundles are evenly arranged. The diameter of carbon fiber monofilament is about 6-7 $\mu \mathrm{m}$. SiC coating uniformly covers carbon fiber, and the thickness of the SiC coating is about $300 \mathrm{~nm}$.
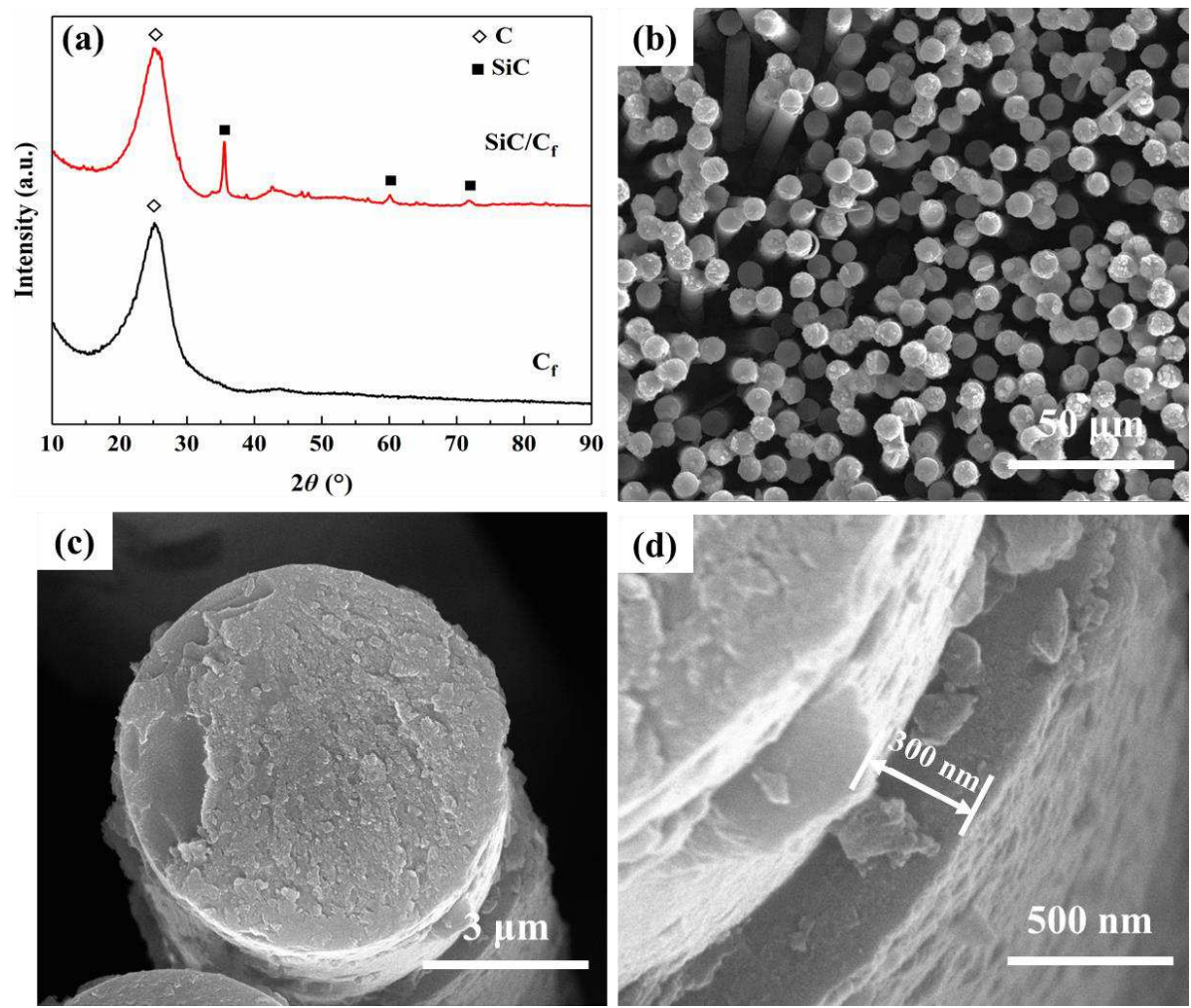
Fig. 2 (a) XRD pattern of $\mathrm{C}_{\mathrm{f}}$ preform and $\mathrm{SiC}$ coating coated $\mathrm{C}_{\mathrm{f}}$ preform; (b)-(d) SEM of $\mathrm{C}_{\mathrm{f}}$ preform and $\mathrm{SiC}$ coating coated $\mathrm{C}_{\mathrm{f}}$ preform at different magnification:

Archimedes drainage method was used to test the bulk density and porosity of $\mathrm{C}_{\mathrm{f}} / \mathrm{SiC} / \mathrm{SiHfBOC}$ composites under different PIP cycle times. The specific results are shown in Table 1. With the increase of PIP cycle times, the density of $\mathrm{C}_{\mathrm{f}} / \mathrm{SiC} / \mathrm{SiHfBOC}$ composites increase gradually, while the porosity decreases gradually. The density of untreated $\mathrm{C}_{\mathrm{f}}$ preform is $0.35 \mathrm{~g} / \mathrm{cm}^{3}$, and its porosity is $85.73 \%$. The density of $\mathrm{C}_{\mathrm{f}} / \mathrm{SiC}$ preform is $0.50 \mathrm{~g} / \mathrm{cm}^{3}$, and its porosity is $74.86 \%$. After the third PIP cycle times, the density of $\mathrm{C}_{\mathrm{f}} / \mathrm{SiC} / \mathrm{SiHfBOC}$ composite was $1.02 \mathrm{~g} / \mathrm{cm}^{3}$, and its porosity was $47.98 \%$. The density of $\mathrm{C}_{\mathrm{f}} / \mathrm{SiC} / \mathrm{SiHfBOC}$ composites increased by about $0.12 \mathrm{~g} / \mathrm{cm}^{3}$ after the third to fifth PIP cycle times, and its density growth rate gradually slowed down. After the seventh PIP cycle times, the density of $\mathrm{C}_{\mathrm{f}} / \mathrm{SiC} / \mathrm{SiHfBOC}$ composites increased only by $0.03 \mathrm{~g} / \mathrm{cm}^{3}$, so the density of $\mathrm{C}_{\mathrm{f}} / \mathrm{SiC} / \mathrm{SiHfBOC}$ composites has reached the upper limit.

Table 1 Density and porosity of $\mathrm{C}_{\mathrm{f}}$ preform, $\mathrm{C}_{\mathrm{f}} / \mathrm{SiC}$ preform and $\mathrm{C}_{\mathrm{f}} / \mathrm{SiC} / \mathrm{SiHfBOC}$ composites

\begin{tabular}{cccc}
\hline Sample & Cycle times of PIP & Density $\left(\mathrm{g} / \mathrm{cm}^{3}\right)$ & Porosity $(\%)$ \\
\hline $\mathrm{C}_{\mathrm{f}}$ & 0 & 0.35 & 85.73 \\
$\mathrm{C}_{\mathrm{f}} / \mathrm{SiC}$ & 0 & 0.50 & 74.86 \\
$\mathrm{C}_{\mathrm{f}} / \mathrm{SiC} / \mathrm{SiHfBOC}-3$ & 3 & 1.02 & 47.98 \\
$\mathrm{C}_{\mathrm{f}} / \mathrm{SiC} / \mathrm{SiHfBOC}-4$ & 4 & 1.15 & 41.35 \\
$\mathrm{C}_{\mathrm{f}} / \mathrm{SiC} / \mathrm{SiHfBOC}-5$ & 5 & 1.27 & 35.23 \\
$\mathrm{C}_{\mathrm{f}} / \mathrm{SiC} / \mathrm{SiHfBOC}-6$ & 6 & 1.37 & 30.13 \\
$\mathrm{C}_{\mathrm{f}} / \mathrm{SiC} / \mathrm{SiHfBOC}-7$ & 7 & 1.40 & 28.60 \\
\hline
\end{tabular}

Figure 3 are SEM images of $\mathrm{C}_{\mathrm{f}} / \mathrm{SiC} / \mathrm{SiHfBOC}$ composites after different PIP cycle times. Combined with Table 1, the density of the composite increases with the increase of PIP cycle times. In Fig. 3 (a), the $\mathrm{C}_{\mathrm{f}} / \mathrm{SiC} / \mathrm{SiHfBOC}-4$ was prepared after four PIP cycle times, with a density of $1.15 \mathrm{~g} / \mathrm{cm}^{3}$ and a porosity of $41.35 \%$. Therefore, a great number of pores can be observed in the fiber preform body, and many carbon fibers have not been filled by SiHfBOC ceramics. The $\mathrm{C}_{\mathrm{f}} / \mathrm{SiC} / \mathrm{SiHfBOC}-5$ was prepared after five PIP cycle times, with a density of $1.27 \mathrm{~g} / \mathrm{cm}^{3}$ and a porosity of $36.84 \%$ (Fig. 3 (b)). However, there are still many holes in the composite, and it is observed that the carbon fiber not coated by SiHfBOC ceramic has decreased significantly. The $\mathrm{C}_{\mathrm{f}} / \mathrm{SiC} / \mathrm{SiHfBOC}-6$ was prepared after 
six PIP cycle times. Its density is increased to $1.37 \mathrm{~g} / \mathrm{cm}^{3}$, and the porosity is $33.44 \%$ (Fig. 3(c)). It is observed that the pores in the composite have been further reduced, and most of the carbon fibers are covered by SiHfBOC ceramics, and the internal filling is relatively complete. The $\mathrm{C}_{\mathrm{f}} / \mathrm{SiC} / \mathrm{SiHfBOC}-7$ was prepared after seven PIP cycle times as in Fig. 3 (d), and the surface of the carbon fiber in the composite material is completely wrapped by $\mathrm{SiHfBOC}$ ceramic. The density of $\mathrm{C}_{\mathrm{f}} / \mathrm{SiC} / \mathrm{SiHfBOC}$ composites increased was not obvious, which was $1.40 \mathrm{~g} / \mathrm{cm}^{3}$, and its porosity was $28.87 \%$. SiHfBOC ceramics covered most of the carbon fibers, that was, the composites were filled with SiHfBOC ceramic matrix. There are only a few holes in the composite, and the maximum pore width is about 3 $\mu \mathrm{m}$. With the increase of PIP cycle times, the spacing of fibers is uniform, and the surface pores are gradually reduced.
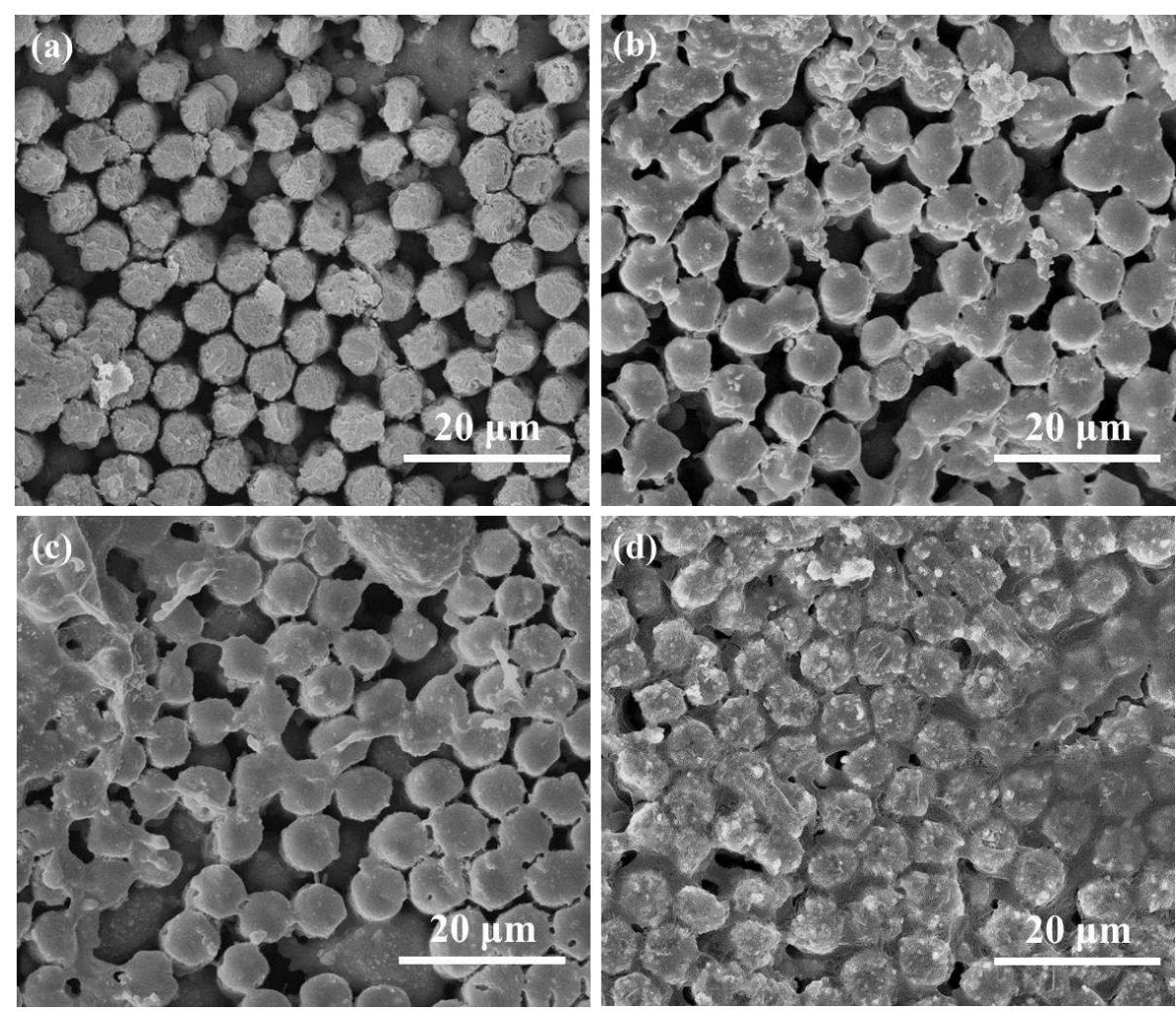

Fig. 3 SEM of $\mathrm{C}_{\mathrm{f}} / \mathrm{SiC} / \mathrm{SiHfBOC}$ composites after different PIP cycle times: (a) 4 PIP cycle times, (b) 5 PIP cycle times, (c) 6 PIP cycle times, (d)7 PIP cycle times

It is found that the microstructure and density of the composites can be controlled by the different PIP cycle times, and the macro and micropores in the composites are greatly reduced after seven times of impregnation and pyrolysis. 


\subsection{Study and analysis of oxidation resistance of $\mathrm{C}_{\mathrm{f}} / \mathrm{SiC} / \mathrm{SiHfBOC}$ composites}

The oxidation behavior of $\mathrm{C}_{\mathrm{f}} / \mathrm{SiC} / \mathrm{SiHfBOC}$ composites at different PIP cycle times are evaluated by XRD and SEM. As shown in Fig. 4, the XRD phase diagram of $\mathrm{C}_{\mathrm{f}} / \mathrm{SiC} / \mathrm{SiHfBOC}-7$ composite is oxidized at $1100{ }^{\circ} \mathrm{C}$ for $10 \mathrm{~min}$. It indicates that not only the diffraction peaks of $\mathrm{SiC}$ and $\mathrm{HfO}_{2}$ are detected [27], but also the diffraction peaks of $\mathrm{HfSiO}_{4}$ are detected at $20.0^{\circ}, 27.1^{\circ}, 44.0^{\circ}$, and $53.7^{\circ}$ after oxidation test [28].

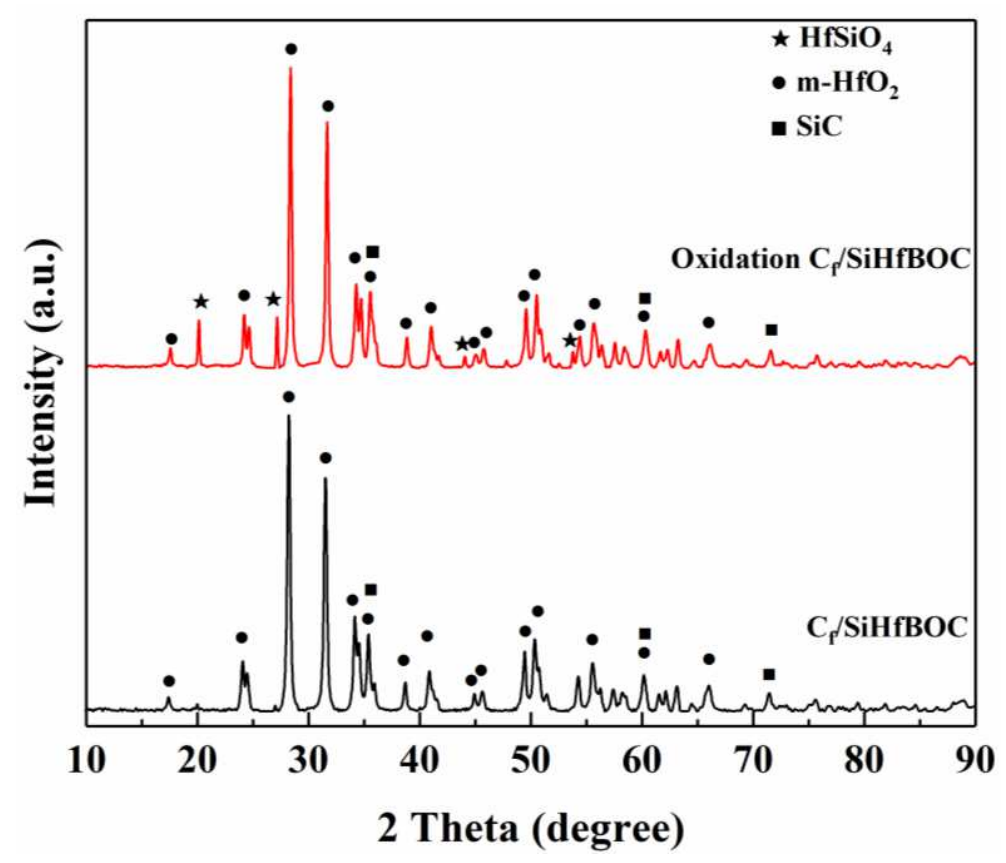

Fig. 4 XRD pattern of $\mathrm{C}_{\mathrm{f}} / \mathrm{SiC} / \mathrm{SiHfBOC}-7$ composites before and after oxidation

The SiHfBOC ceramic content in the sample was less (Figs. 5 (a) and (b)), and foamy oxidation products were formed after oxidation at $1100{ }^{\circ} \mathrm{C}$ for $10 \mathrm{~min}$. In Fig. 5 (c), filamentous oxidation products and obvious pores were observed. The pores on the surface of the samples decrease obviously when PIP cycle times reach 7 times (Fig.5(d)). From the local enlarged Fig. 5 (e), the surface of carbon fiber in the composite is completely wrapped by SiHfBOC ceramic, and the SiHfBOC ceramic on the surface of carbon fiber is oxidized by $\mathrm{O}_{2}$ to form particles with different volumes. In Fig. 5, the $\mathrm{C}_{\mathrm{f}} / \mathrm{SiC} / \mathrm{SiHfBOC}$ composites were gradually filled and the surface was gradually dense after oxidation, as the increase of PIP cycle times. There were filamentous oxidation products, and the pores were also more obvious (Fig. 5 (c)). The pores on the surface of $\mathrm{C}_{\mathrm{f}} / \mathrm{SiC} / \mathrm{SiHfBOC}-7$ were significantly reduced after oxidation. From Fig. 5 (e), the SiHfBOC ceramic on the surface of the carbon fiber are oxidized 
to form particles with different volumes. Fig. 5 (e) shows the weight retention ratio of $\mathrm{C}_{\mathrm{f}} / \mathrm{SiC} / \mathrm{SiHfBOC}$ composites with different PIP cycle times after oxidation. The weight retention ratio of the composite material increases from $93.43 \%$ to $98.75 \%$, when the PIP cycle times increase from 4 to 7. Combined with Fig. 5 and Table 1, it can be found that the pore of the $\mathrm{C}_{\mathrm{f}} / \mathrm{SiC} / \mathrm{SiHfBOC}$ composites surfaces gradually decreases with the increase of PIP cycle times. At the same time, the contact area between carbon fiber and oxygen is gradually decreasing, so the oxidation resistance of the composite material is also improved.
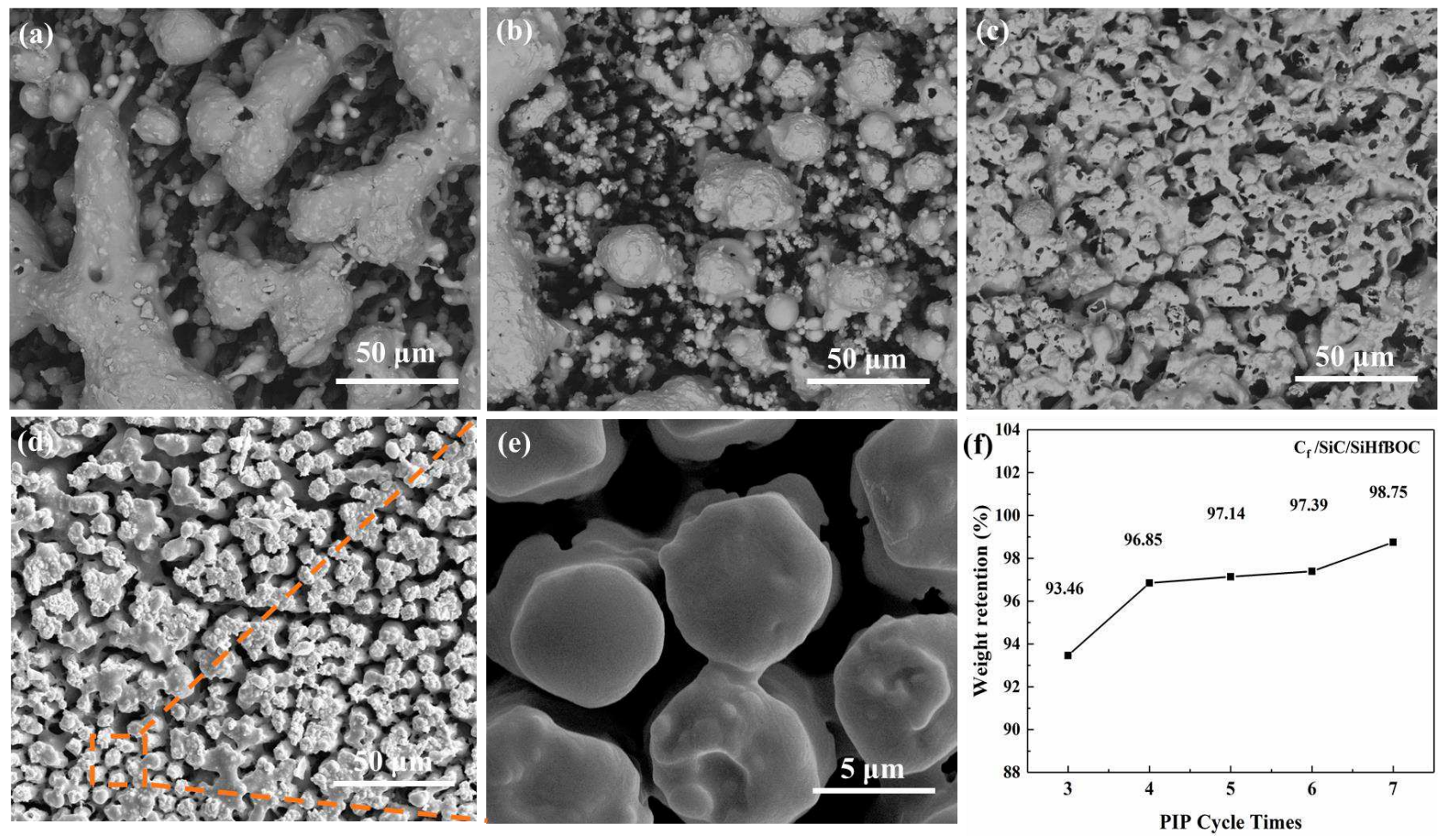

Fig. 5 SEM images and weight retention ratio of $\mathrm{C}_{\mathrm{f}} / \mathrm{SiC} / \mathrm{SiHfBOC}$ composites with different densities oxidized at $1100{ }^{\circ} \mathrm{C}$ for 10 min: (a) 4 PIP cycle times, (b) 5 PIP cycle times, (c) 6 PIP cycle times, (d), (e) 7 PIP cycle times, (f) weight retention ratio

Figure 6 exhibits the SEM image and EDS surface scanning analysis of the $\mathrm{C}_{\mathrm{f}} / \mathrm{SiC} / \mathrm{SiHfBOC}$ 7after oxidation at $1100{ }^{\circ} \mathrm{C}$ for 10 min. In Figs. 6 (a) and (g), there are many spherical particles attached to the top of the carbon fiber in $\mathrm{C}_{\mathrm{f}} / \mathrm{SiC} / \mathrm{SiHfBOC}$ composites, which are similar in volume and evenly distributed. The EDS surface scanning results of the oxidized composites are shown in Fig. 6 (b-f), from which the distribution position and uniformity of $\mathrm{Si}, \mathrm{Hf}, \mathrm{B}, \mathrm{O}$, and $\mathrm{C}$ on the z-direction surface of the oxidized $\mathrm{C}_{\mathrm{f}} / \mathrm{SiC} / \mathrm{SiHfBOC}$ composites can be seen. Combined with the atomic content 
ratio in Fig. 6 (h), the $\mathrm{Si}, \mathrm{Hf}, \mathrm{O}$, and $\mathrm{C}$ are the most abundant elements, while the $\mathrm{B}$ element is relatively low. This is mainly due to the $\mathrm{B}$ element escaping in the form of $\mathrm{B}_{2} \mathrm{O}_{3}$ during the oxidation process.

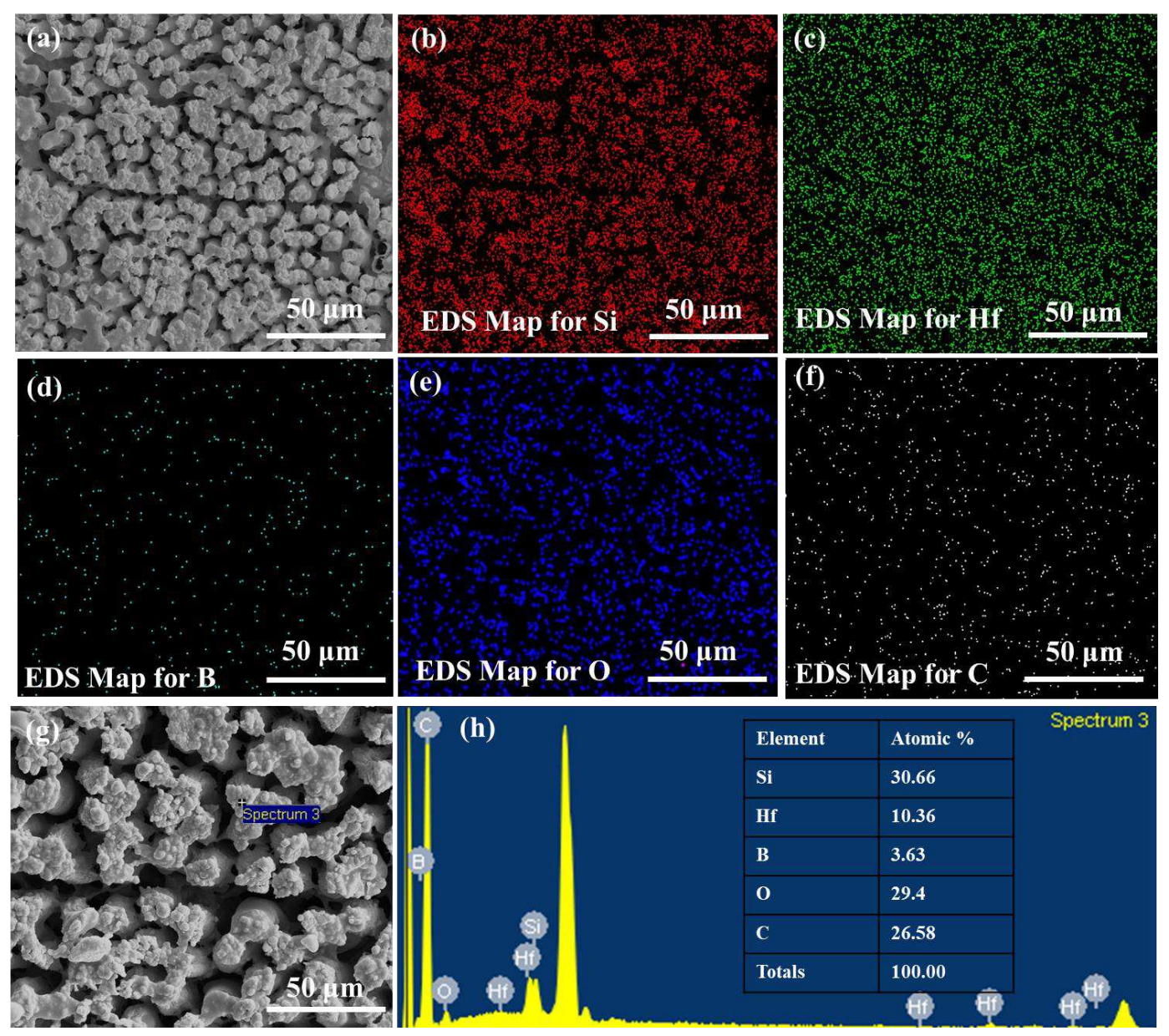

Fig. 6 SEM images and EDS diagram of composite materials after oxidation at $1100{ }^{\circ} \mathrm{C}$ for $10 \mathrm{~min}$

The $\mathrm{C}_{\mathrm{f}} / \mathrm{SiC} / \mathrm{SiHfBOC}-7$ samples were subjected to a static oxidation treatment in a muffle furnace at $1200{ }^{\circ} \mathrm{C}, 1300{ }^{\circ} \mathrm{C}, 1400{ }^{\circ} \mathrm{C}$, and $1500{ }^{\circ} \mathrm{C}$ for $10 \mathrm{~min}$, respectively. The micromorphology of samples after static oxidation treatment at different temperatures are shown in Fig. 7. There are bare $\mathrm{SiC} / \mathrm{C}_{\mathrm{f}}$ and large pores on the surface of the samples after oxidation at $1200{ }^{\circ} \mathrm{C}$ (Figs. 7 (a) and $7(\mathrm{e})$ ), which further forms oxygen channels to accelerate the internal oxidation of the composite. The surface of the sample with the same density is gradually filled and coated by the molten oxide layer (Figs. 7 (b)-7 (d) and 7 (f)-7 (h)), with the increase of oxidation temperature, so its pores gradually decrease. After oxidation at $1500{ }^{\circ} \mathrm{C}$ for $10 \mathrm{~min}$, a dense oxide film has been formed on the surface of the sample. 

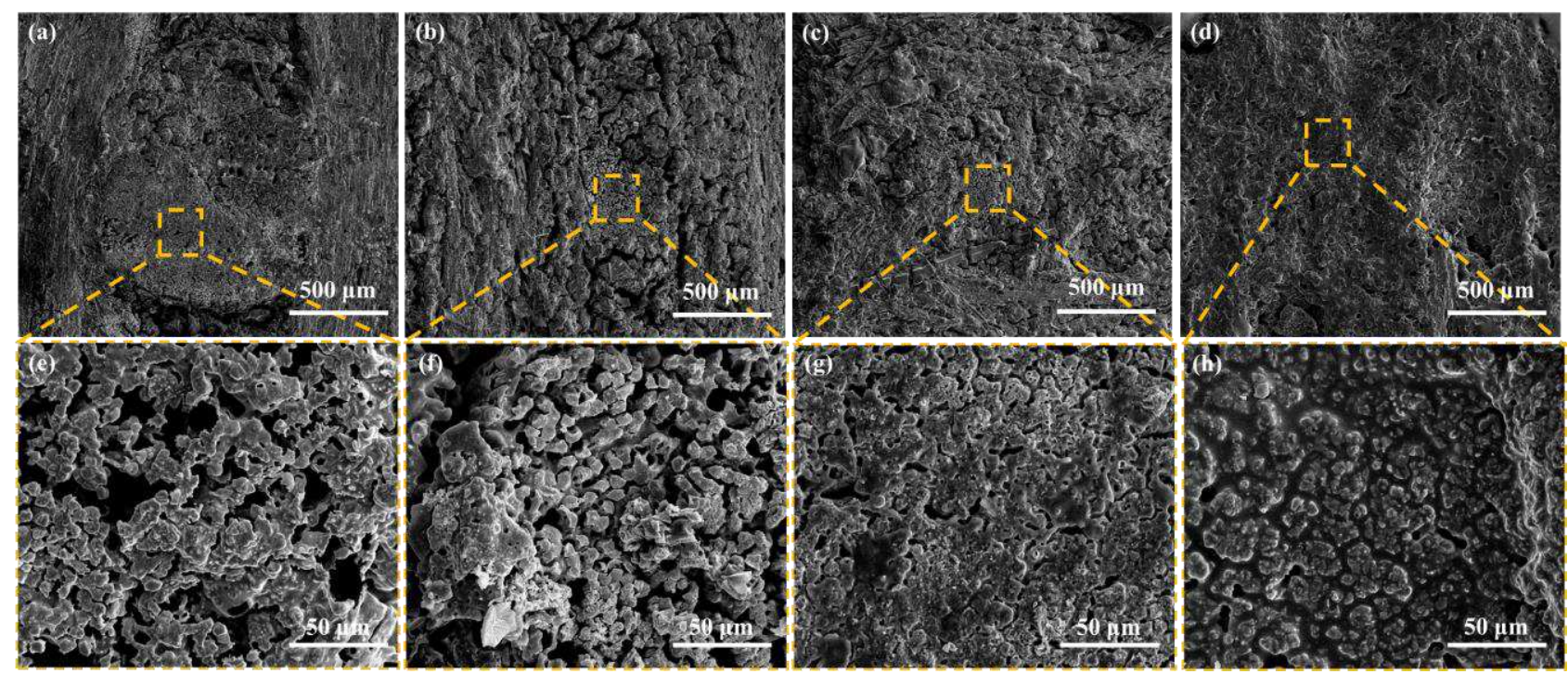

Fig. $7 \mathrm{SEM}$ images of $\mathrm{C}_{\mathrm{f}} / \mathrm{SiC} / \mathrm{SiHfBOC}$ composites after $10 \mathrm{~min}$ of oxidation at different oxidation temperatures:

$$
\text { (a, e) } 1200{ }^{\circ} \mathrm{C},(\mathrm{b}, \mathrm{f}) 1300{ }^{\circ} \mathrm{C},(\mathrm{e}, \mathrm{g}) 1400{ }^{\circ} \mathrm{C},(\mathrm{d}, \mathrm{h}) 1500{ }^{\circ} \mathrm{C}
$$

Fig. 8 shows the XRD pattern and weight retention ratio of the $\mathrm{C}_{\mathrm{f}} / \mathrm{SiC} / \mathrm{SiHfBOC}$ composites after oxidation at $1200{ }^{\circ} \mathrm{C}, 1300{ }^{\circ} \mathrm{C}, 1400{ }^{\circ} \mathrm{C}$, and $1500{ }^{\circ} \mathrm{C}$ for $10 \mathrm{~min}$. The oxidized sample is mainly composed of $\mathrm{SiC}, \mathrm{m}-\mathrm{HfO}_{2}$, and $\mathrm{HfSiO}_{4}$, where the diffraction peaks of $\mathrm{SiC}$ and part of the diffraction peaks of $\mathrm{HfSiO}_{4}$ overlap (Fig. 8(a)). When the oxidation temperature is $1200{ }^{\circ} \mathrm{C}$, the $\mathrm{m}-\mathrm{HfO}_{2}$ in the sample is the main crystalline phase. As the oxidation temperature increases, it is found that the diffraction peak of $\mathrm{m}-\mathrm{HfO}_{2}$ gradually decreases, and the diffraction peak of $\mathrm{HfSiO}_{4}$ gradually increases. This indicates that $\mathrm{m}-\mathrm{HfO}_{2}$ and $\mathrm{SiO}_{2}$ in $\mathrm{C}_{\mathrm{f}} / \mathrm{SiC} / \mathrm{SiHfBOC}$ composites are more likely to react to form $\mathrm{HfSiO}_{4}$ in an oxidizing environment with higher temperatures. The weight retention ratio of the composite material decreases from $96.05 \%$ to $94.85 \%$ (Fig. 8 (b)), when the oxidation temperature increases from $1200{ }^{\circ} \mathrm{C}$ to $1500{ }^{\circ} \mathrm{C}$. With the increase of oxidation temperature, the weight retention ratio of $\mathrm{C}_{\mathrm{f}} / \mathrm{SiC} / \mathrm{SiHfBOC}$ composites gradually decreases, but the decreasing range is small. It shows that as the oxidation temperature increases, the surface dense oxide film of the sample reacts with oxygen gradually becomes severe, so the oxidation resistance of the $\mathrm{C}_{\mathrm{f}} / \mathrm{SiC} / \mathrm{SiHfBOC}$ composites at high-temperature also decreases. 

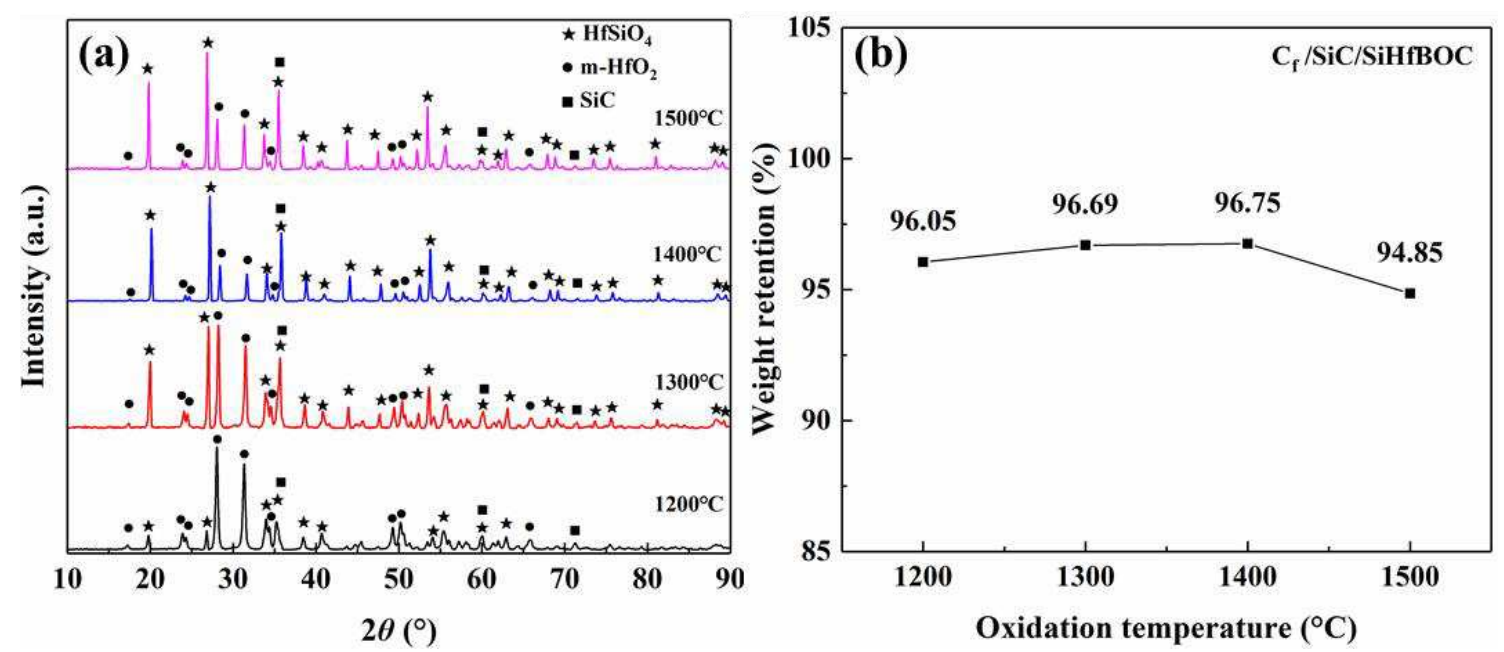

Fig. $8 \mathrm{XRD}$ pattern and weight retention ratio of $\mathrm{C}_{\mathrm{f}} / \mathrm{SiC} / \mathrm{SiHfBOC}$ composites after $10 \mathrm{~min}$ oxidation at different oxidation temperatures:(a) XRD pattern, (b) weight retention ratio

The micromorphology of the $\mathrm{C}_{\mathrm{f}} / \mathrm{SiC} / \mathrm{SiHfBOC}-7$ composites after static oxidation treatment at $1500{ }^{\circ} \mathrm{C}$ in a muffle furnace for $30 \mathrm{~min}, 60 \mathrm{~min}, 90 \mathrm{~min}$, and $120 \mathrm{~min}$ is shown in Fig. 9. As the oxidation time increases, the surface of the composite material becomes denser and the pores are gradually filled. In Figs. 9 (a) and 9 (e), the sample oxidized at $1500{ }^{\circ} \mathrm{C}$ for $30 \mathrm{~min}$ has no obvious pores, but the surface is rough. In Figs. 9 (b) and 9 (f), the sample oxidized at $1500{ }^{\circ} \mathrm{C}$ for 60 min has some small pores, but the surface roughness decreases. In Figs. 9 (c) and 9 (g), the pores on the surface of the sample after oxidizing at $1500{ }^{\circ} \mathrm{C}$ for 90 minutes are the largest, and the distribution is uneven, but the surface is relatively flat. In Figs. 9 (d) and 9 (h), the pores on the surface of the sample oxidized at $1500{ }^{\circ} \mathrm{C}$ for $120 \mathrm{~min}$ are smaller and the surface is the flattest. The results show that a large amount of $\mathrm{CO}_{2}, \mathrm{CO}, \mathrm{B}_{2} \mathrm{O}_{3}$, and other gases escape during the oxidation process of $\mathrm{C}_{\mathrm{f}} / \mathrm{SiC} / \mathrm{SiHfBOC}-7$ composites, so many pores are formed on the surface of the samples. At the same time, molten $\mathrm{SiO}_{2}$ and borosilicate glass phases are produced under high-temperature oxidation conditions to fill the surface, thereby gradually smoothing and compacting. 

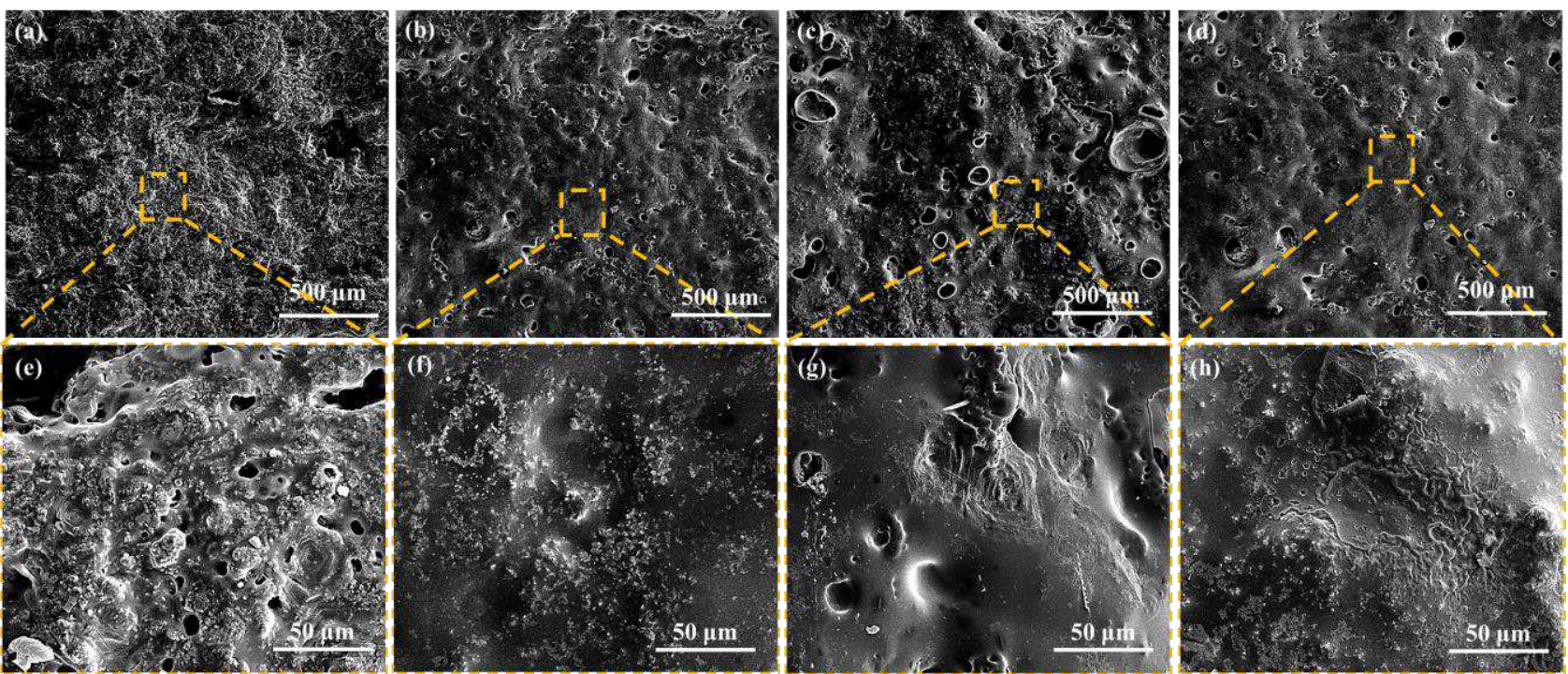

Fig. 9 SEM images of $\mathrm{C}_{\mathrm{f}} / \mathrm{SiC} / \mathrm{SiHfBOC}$ composites after different oxidation time at $1500{ }^{\circ} \mathrm{C}$ :

(a, e) $30 \mathrm{~min},(\mathrm{~b}, \mathrm{f}) 60 \mathrm{~min},(\mathrm{c}, \mathrm{g}) 90 \mathrm{~min},(\mathrm{~d}, \mathrm{~h}) 120 \mathrm{~min}$

Figure 10 (a) exhibits the XRD pattern of the $\mathrm{C}_{\mathrm{f}} / \mathrm{SiC} / \mathrm{SiHfBOC}-7$ composites after oxidation at $1500{ }^{\circ} \mathrm{C}$ for $30 \mathrm{~min}, 60 \mathrm{~min}, 90 \mathrm{~min}$, and $120 \mathrm{~min}$. The diffraction peaks of crystalline $\mathrm{SiO}_{2}$ were observed at $22.0^{\circ}$ in the XRD curves of samples oxidized for $60 \mathrm{~min}, 90 \mathrm{~min}$, and $120 \mathrm{~min}$. Meanwhile, with the increase of oxidation time, the diffraction peaks of crystalline $\mathrm{SiO}_{2}$ and $\mathrm{m}-\mathrm{HfO}_{2}$ gradually decreases, while the diffraction peaks of $\mathrm{HfSiO}_{4}$ gradually increase. It shows that the chemical reaction of crystalline $\mathrm{SiO}_{2}$ and $\mathrm{m}-\mathrm{HfO}_{2}$ is easier to produce $\mathrm{HfSiO}_{4}$ under the condition of long-time high-temperature oxidation. The oxidation products of $\mathrm{C}_{\mathrm{f}} / \mathrm{SiC} / \mathrm{SiHfBOC}-7$ composites are mainly composed of $\mathrm{HfSiO}_{4} 、 \mathrm{~m}-\mathrm{HfO}_{2} 、 \mathrm{SiO}_{2}$ and $\mathrm{SiC}$. In Fig. 10 (b), the weight retention of $\mathrm{C}_{\mathrm{f}} / \mathrm{SiC} / \mathrm{SiHfBOC}-7$ composites first increase, then decreases, and then increases with the extension of oxidation time, but it generally shows a decreasing trend. On the whole, the weight reduction of $\mathrm{C}_{\mathrm{f}} / \mathrm{SiC} / \mathrm{SiHfBOC}-7$ composites is very small. According to the analysis in Fig. 9, the $\mathrm{C}_{\mathrm{f}} / \mathrm{SiC} / \mathrm{SiHfBOC}-7$ composites is seriously oxidized with the prolongation of oxidation time, hightemperature oxidation resistance is gradually weakened. It also indicates that $\mathrm{C}_{\mathrm{f}} / \mathrm{SiC} / \mathrm{SiHfBOC}-7$ composites still have a high weight retention ratio after long time oxidation at $1500{ }^{\circ} \mathrm{C}$. However, the weight retention ratio of $\mathrm{C}_{\mathrm{f}} / \mathrm{SiC} / \mathrm{SiHfBOC}-7$ composites after oxidation at $1500{ }^{\circ} \mathrm{C}$ for $120 \mathrm{~min}$ is roughly the same as that after oxidation for $90 \mathrm{~min}$, indicating that the weight change of the composites after oxidation for 90 min reaches a dynamic equilibrium. 

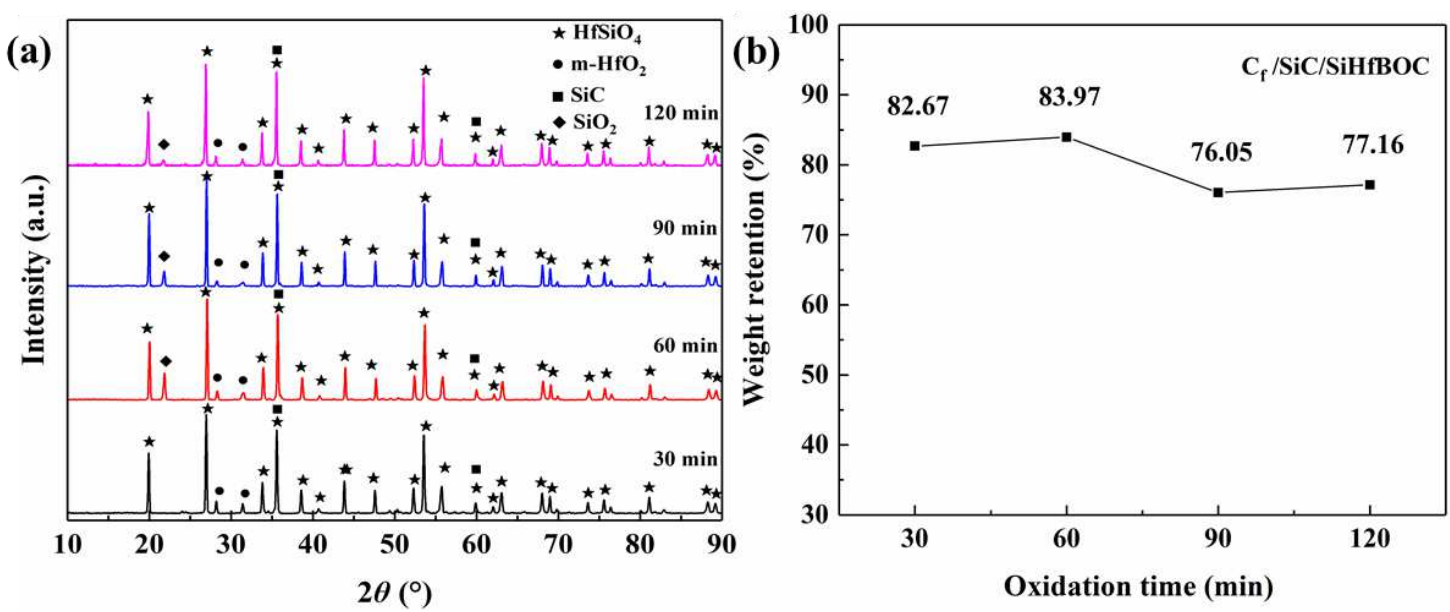

Fig. $10 \mathrm{XRD}$ pattern and weight retention ratio of $\mathrm{C}_{\mathrm{f}} / \mathrm{SiC} / \mathrm{SiHfBOC}$ composites after oxidation at $1500{ }^{\circ} \mathrm{C}$ with different oxidation time: (a) XRD pattern, (b) weight retention ratio

The main phases of the $\mathrm{C}_{\mathrm{f}} / \mathrm{SiC} / \mathrm{SiHfBOC}$ composites prepared in this paper mainly include $\mathrm{C}_{\mathrm{f}}$, $\mathrm{SiC}$, $\mathrm{HfO}_{2}, \mathrm{BC}_{\mathrm{x}} \mathrm{O}_{3-\mathrm{x}}, \mathrm{B}(\mathrm{SiO})_{3}$ and $\mathrm{SiO}_{\mathrm{x}} \mathrm{C}_{\mathrm{y}}$, according to the above data and reference [2,14,15,28-32]. Therefore, the high-temperature oxidation mechanism of $\mathrm{C}_{\mathrm{f}} / \mathrm{SiC} / \mathrm{SiHfBOC}$ composites are analyzed, and the possible chemical reaction formulas under high-temperature oxidation conditions are as follows:

$$
\begin{gathered}
\mathrm{C}_{f}+\mathrm{O}_{2} \rightarrow \mathrm{CO}(g) \\
\mathrm{C}_{f}+\mathrm{O}_{2} \rightarrow \mathrm{CO}_{2}(g) \\
\mathrm{B}_{2} \mathrm{O}_{3}(l) \rightarrow \mathrm{B}_{2} \mathrm{O}_{3}(g) \\
\mathrm{SiO}_{x} \mathrm{C}_{y}(s)+\mathrm{O}_{2}(g) \rightarrow \mathrm{SiO}_{2}(s)+\mathrm{SiC}(s) \\
\mathrm{BC}_{x} \mathrm{O}_{3-x}(s)+\mathrm{O}_{2}(g) \rightarrow \mathrm{B}_{2} \mathrm{O}_{3}(g)+\mathrm{CO}_{2}(g) \\
\mathrm{B}\left(\mathrm{SiO}_{3}(s)+\mathrm{O}_{2}(g) \rightarrow \mathrm{B}_{2} \mathrm{O}_{3}(g)+\mathrm{SiO}_{2}(s)\right. \\
\mathrm{SiC}_{(}(s)+\mathrm{O}_{2} \rightarrow \mathrm{SiO}_{2}(s)+\mathrm{CO}_{2}(g) \\
\mathrm{SiC}_{(}(\mathrm{s})+\mathrm{O}_{2} \rightarrow \mathrm{SiO}_{2}(s)+\mathrm{CO}(g) \\
\mathrm{HfO}_{2}(s)+\mathrm{SiO}_{2}(s) \rightarrow \mathrm{HfSiO}_{4}(s)
\end{gathered}
$$

Comparing the Gibbs free energy of each phase composition in $\mathrm{C}_{\mathrm{f}} / \mathrm{SiC} / \mathrm{SiHfBOC}$ composites, it is found that the Gibbs free energy of the reaction between $\mathrm{SiC}$ and $\mathrm{O}_{2}$ is the lowest $[33,34]$. Combined 
with the morphology, XRD phase diagram, and the above chemical reaction formula under different oxidation conditions, the oxidation behavior can be divided into three parts:

1. The oxidation temperature rises from room temperature to $1100{ }^{\circ} \mathrm{C}$. Due to the difference in thermal expansion coefficients of each phase's composition and the volatilization of gaseous components, it can be seen from the SEM that there are many cracks and pores on the surface of the composites. Although the generated $\mathrm{B}_{2} \mathrm{O}_{3}$ has a certain fluidity in this temperature range, it can protect the composites to a certain extent. However, due to the low B element content in the material, the defects of the surface of the composites cannot be healed. When the temperature continues to rise, the generated $\mathrm{B}_{2} \mathrm{O}_{3}$ gradually begins to volatilize. The process continues from low temperature to high-temperature, while a small amount of $\mathrm{HfSiO}_{4}$ is generated.

2. The oxidation temperature rises from $1200{ }^{\circ} \mathrm{C}$ to $1500{ }^{\circ} \mathrm{C}$. The $\mathrm{SiO}_{2}$ in the composites begin to melt, so the fluidity of the surface of the composites is greatly improved. The cracks on the surface of the composites are gradually healed, leaving only a few holes. At this time, the oxygen channel is gradually blocked, so that oxygen atoms can no longer enter the interior of the composites to react. Therefore, the thickness of the oxide layer decreases, and the generation of $\mathrm{HfSiO}_{4}$ gradually increases with increasing temperature.

3. After oxidation at $1500{ }^{\circ} \mathrm{C}$ for $30 \mathrm{~min}$, there are many pores on the surface of the composites. After 60 minutes of oxidation, the amorphous $\mathrm{SiO}_{2}$ is oxidized to crystalline $\mathrm{SiO}_{2}$. However, with the extension of the oxidation time, the peak intensity of crystalline $\mathrm{SiO}_{2}$ gradually weakens, while the content of $\mathrm{HfSiO}_{4}$ gradually increased.

\subsection{Characterization of mechanical properties and analysis of strengthening-toughening of $\mathrm{C}_{\mathrm{f}} / \mathrm{SiC} / \mathrm{SiHfBOC}$ composites}

Figure 11 shows the compressive strength of $\mathrm{C}_{\mathrm{f}} / \mathrm{SiC} / \mathrm{SiHfBOC}$ composites in $\mathrm{x} / \mathrm{y}$ and $\mathrm{z}$ directions under different PIP cycle times. The mechanical properties of the $\mathrm{C}_{\mathrm{f}} / \mathrm{SiC} / \mathrm{SiHfBOC}$ composites were improved with the increase of PIP cycle times. The compressive strength of samples after three PIP cycle times in the $\mathrm{x} / \mathrm{y}$ direction and z-direction is $31.32 \pm 6.12 \mathrm{MPa}$ and $9.31 \pm 1.23 \mathrm{MPa}$ respectively. After five PIP cycle times, the compressive strength of $\mathrm{C}_{\mathrm{f}} / \mathrm{SiC} / \mathrm{SiHfBOC}-5$ was $71.97 \pm 8.97 \mathrm{MPa}$ in the $\mathrm{x} / \mathrm{y}$ direction, and $23.92 \pm 4.11 \mathrm{MPa}$ in the $\mathrm{z}$-direction. The density of $\mathrm{C}_{\mathrm{f}} / \mathrm{SiC} / \mathrm{SiHfBOC}-7$ was the 
highest after seven PIP cycle times, and the compressive strength of $\mathrm{C}_{\mathrm{f}} / \mathrm{SiC} / \mathrm{SiHfBOC}-7$ increased slightly in the $\mathrm{x} / \mathrm{y}$ direction and z-direction to $77.56 \pm 8.56 \mathrm{MPa}$ and $40.03 \pm 5.48 \mathrm{MPa}$, respectively. The increase of compressive strength decreases with the increase of PIP cycle times. As shown in Fig. 11 , the compressive strength of $\mathrm{C}_{\mathrm{f}} / \mathrm{SiC} / \mathrm{SiHfBOC}$ composites in $\mathrm{x} / \mathrm{y}$ direction and $\mathrm{z}$-direction is positively correlated with PIP cycle times of the sample. Besides, the compressive property of the samples with the same PIP cycle times in the $\mathrm{x} / \mathrm{y}$ direction is higher than that in the $\mathrm{z}$-direction. The main reason is that the fiber arrangement mode of the three-dimensional carbon fiber preform is that the twodimensional carbon fiber cloth is arranged along the $\mathrm{z}$-direction, and the $\mathrm{z}$-direction is the needling process.

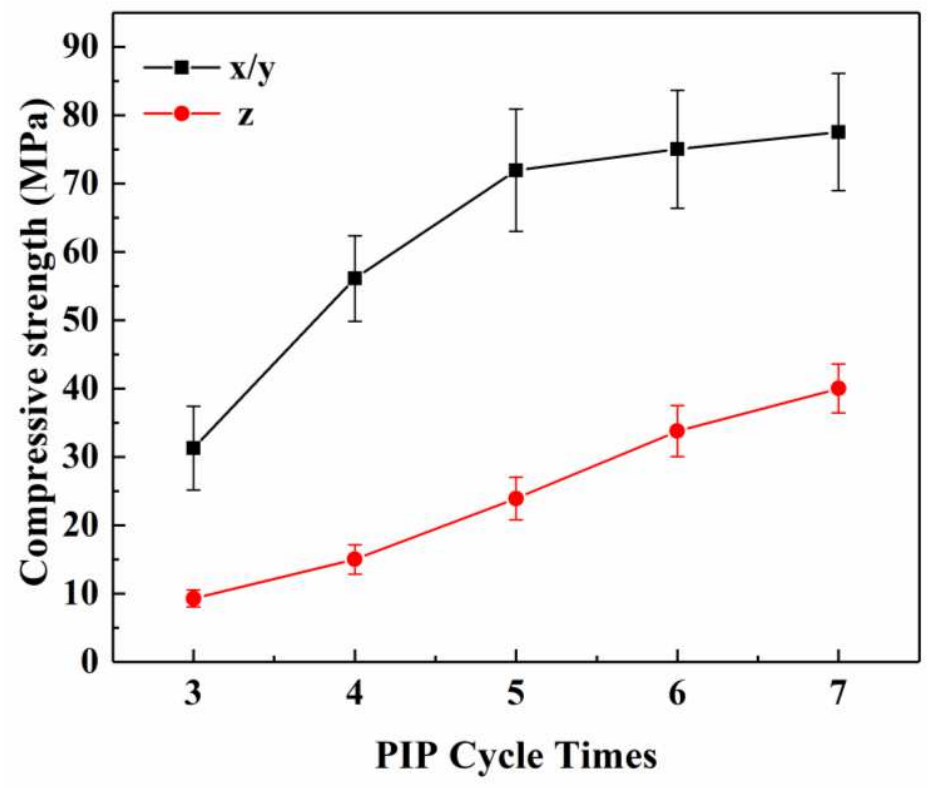

Fig. 11 Compressive strength of $\mathrm{C}_{\mathrm{f}} / \mathrm{SiC} / \mathrm{SiHfBOC}$ composites with different densities

In Fig. 12, the compressive strength-strain curves of $\mathrm{C}_{\mathrm{f}} / \mathrm{SiC} / \mathrm{SiHfBOC}$ composites consist of three stages: (1) In the elastic strain stage, the whole structure of the sample is not damaged until the compressive strength reaches the maximum value, and the stress-strain curve appears inflection point. Then the internal structure of $\mathrm{C}_{\mathrm{f}} / \mathrm{SiC} / \mathrm{SiHfBOC}$ composite began to destroy. The initial corresponding slope is the elastic modulus of the composites, that is the compressive modulus; (2) The yield stage of $\mathrm{C}_{\mathrm{f}} / \mathrm{SiC} / \mathrm{SiHfBOC}$ composites are also called the strain strengthening stage, where irreversible inelastic deformation occurs; (3) In the destruction stage, the composite material is seriously damaged and the structure collapses. 

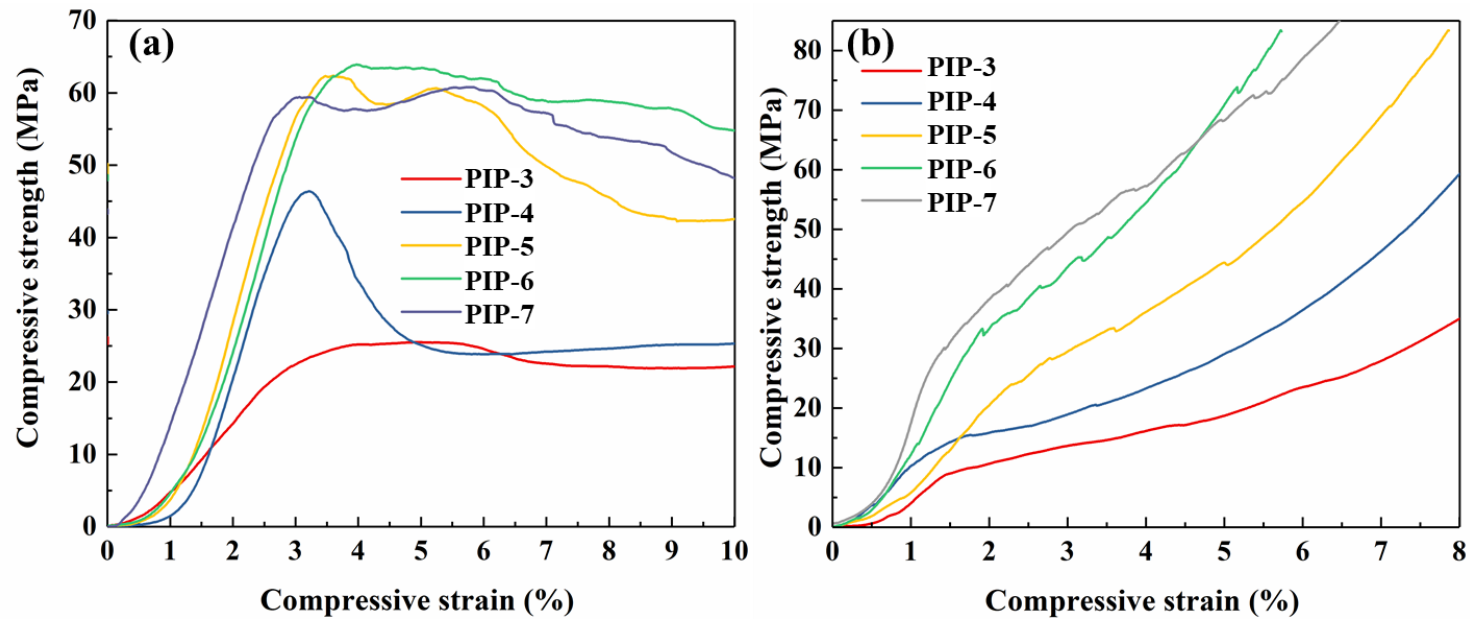

Fig. 12 Compressive strength-strain curves of $\mathrm{C}_{\mathrm{f}} / \mathrm{SiC} / \mathrm{SiHfBOC}$ composites with different PIP cycle times:

(a) $\mathrm{x} / \mathrm{y}$ direction (b) $\mathrm{z}$ direction

The compressive strength-strain curve in the x/y direction is obvious changed (Fig. 12 (a)), with the increase of PIP cycle times of $\mathrm{C}_{\mathrm{f}} / \mathrm{SiC} / \mathrm{SiHfBOC}$ composites. It can be seen from the first elastic strain stage that the compressive strength reaches the maximum value when the PIP cycle times is 6 , and the composite itself has a large deformation. There are only two stages in the compressive strength-strain curve of $\mathrm{C}_{\mathrm{f}} / \mathrm{SiC} / \mathrm{SiHfBOC}$ composites in the $\mathrm{z}$-direction (Fig. 12 (b)), namely, elastic stage and yield stage. The reason is that only part of the fiber bundle breaks in the z-direction of the sample under the external load, while the fiber cloth layers perpendicular to the $\mathrm{z}$-direction start to stack without being damaged, so the stress-strain curve of the composite rises continuously.

As shown in Fig. 13 (a), the $\mathrm{x} / \mathrm{y}$ and $\mathrm{z}$ flexural strengths of $\mathrm{C}_{\mathrm{f}} / \mathrm{SiC} / \mathrm{SiHfBOC}-3$ composites are $43.12 \pm 4.18 \mathrm{MPa}$ and $4.93 \pm 0.85 \mathrm{Mpa}$, respectively. The flexural strength of $\mathrm{C}_{\mathrm{f}} / \mathrm{SiC} / \mathrm{SiHfBOC}-5$ composites reaches $51.27 \pm 4.55 \mathrm{MPa}$ in the $\mathrm{x} / \mathrm{y}$ direction and $6.84 \pm 1.44 \mathrm{MPa}$ in the z-direction after five PIP cycle times. The flexural strength of $\mathrm{C}_{\mathrm{f}} / \mathrm{SiC} / \mathrm{SiHfBOC}$ in the $\mathrm{x} / \mathrm{y}$ and $\mathrm{z}$ directions is $59.94 \pm$ 4.24 MPa and $12.47 \pm 2.17 \mathrm{MPa}$ after seven PIP cycle times, respectively. Figure 13 (b) shows the flexural strength-displacement curves of $\mathrm{C}_{\mathrm{f}} / \mathrm{SiC} / \mathrm{SiHfBOC}$ composite after oxidation at five different PIP cycle times. The three stages of flexural strength-displacement curves in the $\mathrm{x} / \mathrm{y}$ direction of $\mathrm{C}_{\mathrm{f}} / \mathrm{SiC} / \mathrm{SiHfBOC}$ composite are obvious with the increase of oxidation temperature. It can be seen from the first elastic stage that the flexural strength of composites reaches the maximum value when the PIP cycle times are the maximum, and the composites themself have a large deformation. 

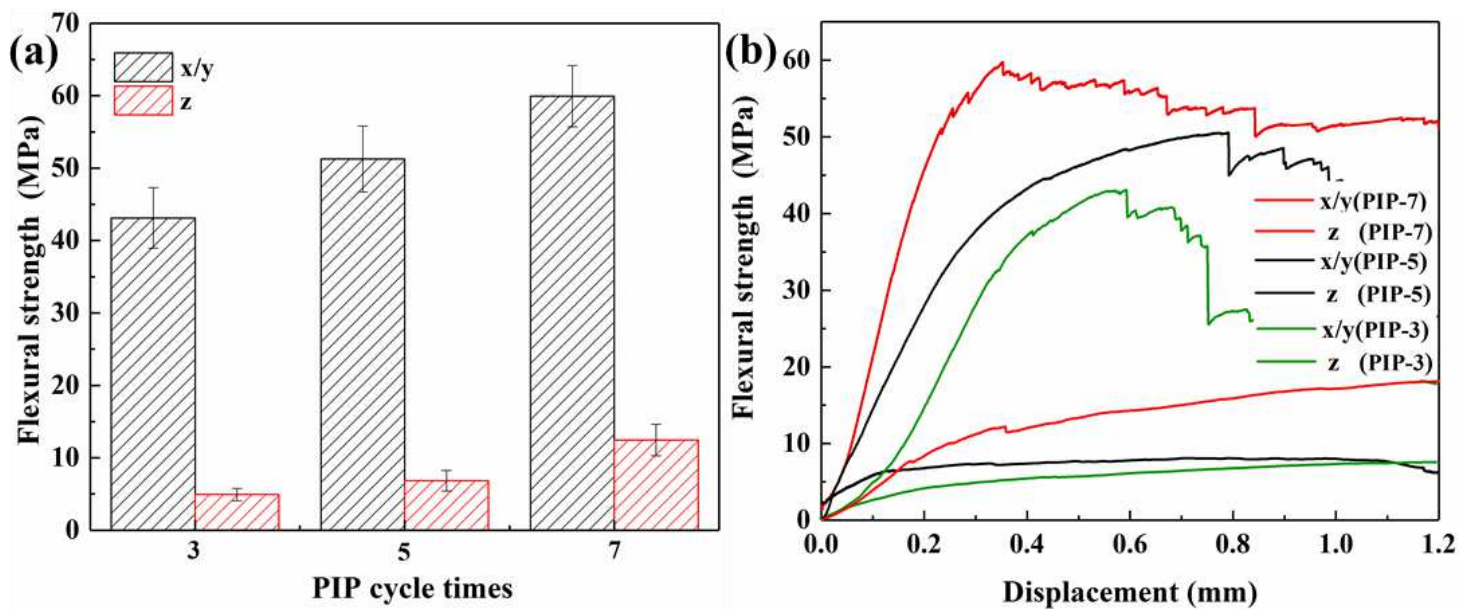

Fig. 13 Flexural strength and flexural strength-displacement curves of $\mathrm{C}_{\mathrm{f}} / \mathrm{SiC} / \mathrm{SiHfBOC}$ composites with different PIP cycle times in the $x / y$ direction and $\mathrm{z}$ direction: (a) flexural strength, (b) flexural strength-displacement curves

The fracture morphology of $\mathrm{C}_{\mathrm{f}} / \mathrm{SiC} / \mathrm{SiHfBOC}$ composites is shown in Fig. 14. In this work, to overcome the intrinsic brittleness of ceramics, continuous carbon fiber was selected as the second phase to toughen. The continuous carbon fibers added to the SiHfBOC ceramic matrix are arranged orderly in the SiHfBOC ceramic matrix, which can greatly improve the flexural strength of $\mathrm{C}_{\mathrm{f}} / \mathrm{SiC} / \mathrm{SiHfBOC}$ composites. During elastic deformation stage process, the continuous carbon fiber absorbs a lot of energy, and most of the mechanical energy absorbed is converted into surface energy, which is mismatched with the ceramic matrix and begins to debond [35]. In Fig. 14 (b), as the load continues to increase, the crack interface between continuous carbon fiber and ceramic matrix begins to loosen, resulting in stress relaxation. The ceramic matrix is damaged and then spalling occurs. The continuous carbon fiber is exposed, which is called the fiber pull-out phenomenon. When the carbon fiber is pulled out, it will continue to absorb external energy, and absorb the most energy. The continuous carbon fiber begins to fracture (Fig. 14 (c)). In the process of carbon fiber fracture, when the crack extends to the surface of carbon fiber, the carbon fiber will continue to absorb energy and deform, until the critical point of carbon fiber fracture, it cannot continue to absorb energy, and finally fracture. After the fracture, the carbon fiber will recover to the original state, and then release the energy absorbed before. It is indicated that the strengthening and toughening mechanism of $\mathrm{C}_{\mathrm{f}} / \mathrm{SiC} / \mathrm{SiHfBOC}$ composites are mainly composed of fiber debonding, fiber pulling out, and fiber 
fracture. The debonding and pullout of continuous carbon fibers play an important role in the failure of $\mathrm{C}_{\mathrm{f}} / \mathrm{SiC} / \mathrm{SiHfBOCceramic} \mathrm{matrix} \mathrm{composites} \mathrm{during} \mathrm{flexural} \mathrm{fracture} \mathrm{experiments.}$
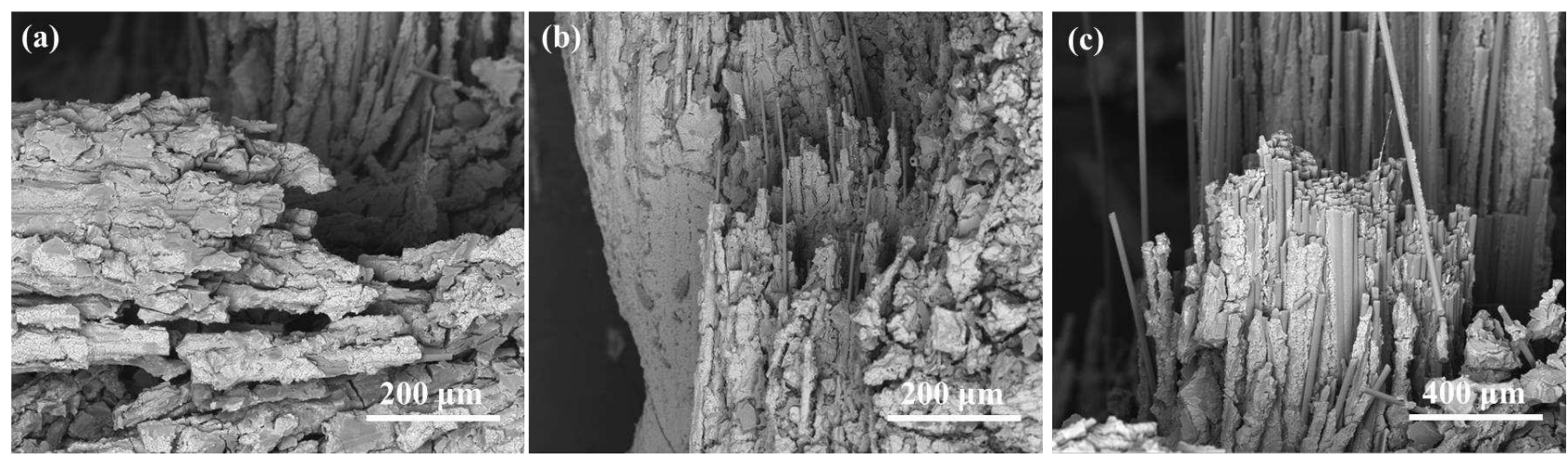

Fig. 14 Fracture morphology of $\mathrm{C}_{\mathrm{f}} / \mathrm{SiC} / \mathrm{SiHfBOC}$ composites: (a) fiber debonding, (b) fiber pulling out, (c) fiber fracture

The compressive strength of $\mathrm{C}_{\mathrm{f}} / \mathrm{SiC} / \mathrm{SiHfBOC}$ composites in $\mathrm{x} / \mathrm{y}$ direction has three stages, which are representative of research. Therefore, the analysis of oxidative compressive strength in $\mathrm{x} / \mathrm{y}$ direction is taken as the research object. The compressive strength and compressive strength-strain curves of $\mathrm{C}_{\mathrm{f}} / \mathrm{SiC} / \mathrm{SiHfBOC}-7$ composites after oxidation at five oxidation temperatures are shown in Fig. 15. The compressive strength in the $\mathrm{x} / \mathrm{y}$ direction of $\mathrm{C}_{\mathrm{f}} / \mathrm{SiC} / \mathrm{SiHfBOC}-7$ composites after oxidation at $1100{ }^{\circ} \mathrm{C}, 1200{ }^{\circ} \mathrm{C}, 1300{ }^{\circ} \mathrm{C}, 1400{ }^{\circ} \mathrm{C}$ and $1500{ }^{\circ} \mathrm{C}$ for $10 \mathrm{~min}$ is $75.16 \pm 8.17 \mathrm{MPa}, 64.93 \pm 7.22 \mathrm{MPa}$, $60.53 \pm 7.01 \mathrm{MPa}, 55.19 \pm 5.25 \mathrm{MPa}, 39.59 \pm 4.78 \mathrm{Mpa}$ (Fig. 15 (a)), respectively. The results show that the compressive strength of $\mathrm{C}_{\mathrm{f}} / \mathrm{SiC} / \mathrm{SiHfBOC}$ composites decreases with the increase of oxidation temperature. The compressive strength of $\mathrm{C}_{\mathrm{f}} / \mathrm{SiC} / \mathrm{SiHfBOC}$ composites decreases with the increase of oxidation temperature. The compressive strength decreased to $96.90 \%$ after oxidation at $1100{ }^{\circ} \mathrm{C}$ and $51.03 \%$ after oxidation at $1500{ }^{\circ} \mathrm{C}$., but it still has high mechanical properties after a short time of high-temperature oxidation. Three stages of the stress-strain curve in the $\mathrm{x} / \mathrm{y}$ direction can be observed (Fig. 15 (b)). In the first elastic stage of all composites, the compressive strength is the largest and the deformation is the smallest, when the oxidation temperature is $1100{ }^{\circ} \mathrm{C}$. 

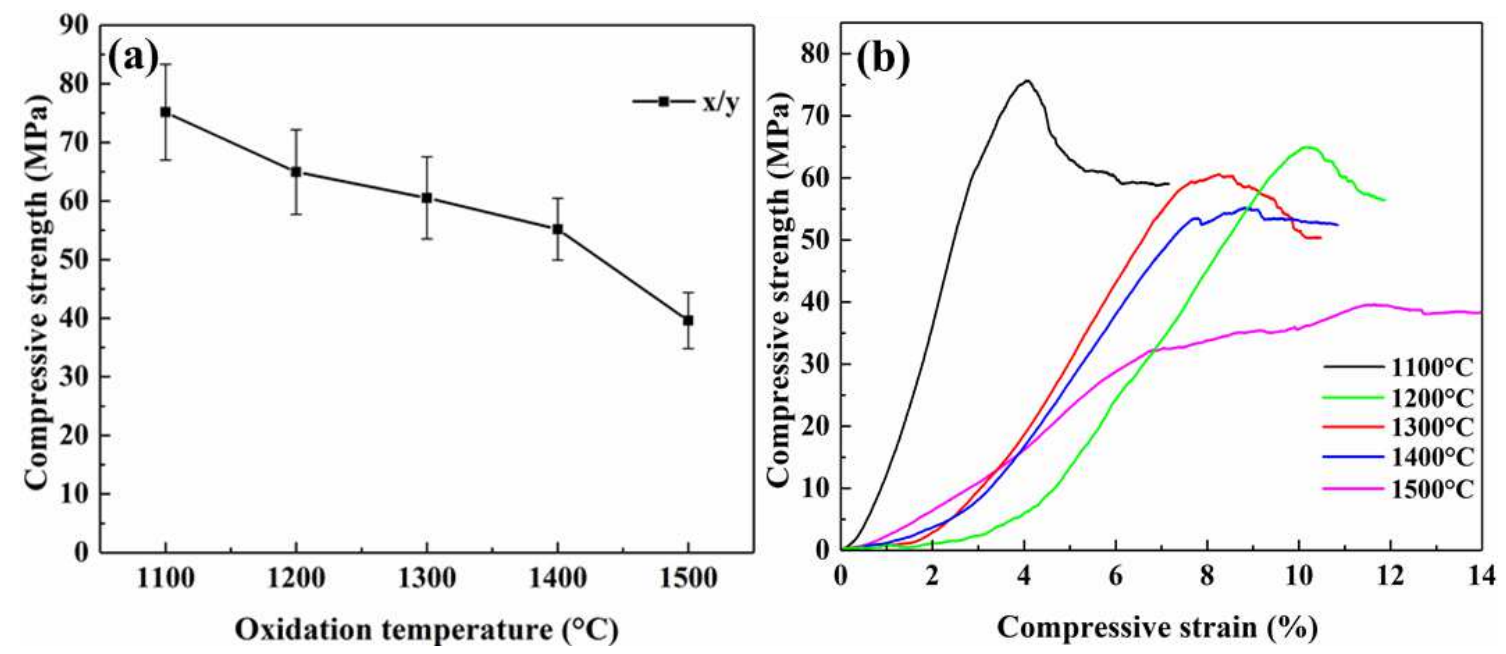

Fig. 15 Compression strength and compressive strength-strain curves of $\mathrm{C}_{\mathrm{f}} / \mathrm{SiC} / \mathrm{SiHfBOC}$ composites in the $\mathrm{x} / \mathrm{y}$ direction at different oxidation temperatures: (a) compression strength, (b) compressive strength-strain curves

Figure 16 exhibits the compressive strength and compressive strength-strain curves of $\mathrm{C}_{\mathrm{f}} / \mathrm{SiC} / \mathrm{SiHfBOC}-7$ composite after four oxidation time at $1500{ }^{\circ} \mathrm{C}$. The compressive strength of $\mathrm{C}_{\mathrm{f}} / \mathrm{SiC} / \mathrm{SiHfBOC}-7$ composite in the $\mathrm{x} / \mathrm{y}$ direction is $30.38 \pm 3.55 \mathrm{MPa}, 23.88 \pm 3.11 \mathrm{MPa}, 18.68 \pm$ 2.34 $\mathrm{MPa}$ and $16.50 \pm 2.08 \mathrm{MPa}$ after oxidation at $1500{ }^{\circ} \mathrm{C}$ for $30 \mathrm{~min}, 60 \mathrm{~min}, 90 \mathrm{~min}$, and $120 \mathrm{~min}$, respectively. The compressive strength decreased to $39.17 \%$ after 30 min oxidation, $24.08 \%$ after 90 min oxidation, and $21.27 \%$ after 120 min oxidation. The results show that the compressive strength of $\mathrm{C}_{\mathrm{f}} / \mathrm{SiC} / \mathrm{SiHfBOC}-7$ composites decreases with the increase of oxidation time, and the compressive strength changes little after oxidation at $1500{ }^{\circ} \mathrm{C}$ for $90 \mathrm{~min}$, and $120 \mathrm{~min}$. Fig. 16 (b) shows the stress-strain curves of $\mathrm{C}_{\mathrm{f}} / \mathrm{SiC} / \mathrm{SiHfBOC}-7$ composites after oxidation at $1500{ }^{\circ} \mathrm{C}$ for a different time. Three stages of the stress-strain curve in the $\mathrm{x} / \mathrm{y}$ direction can be seen (Fig. 16 (b)), with the increase of oxidation time. From the first elastic stage, when the oxidation time is $30 \mathrm{~min}$, the compressive strength reaches the maximum value, and the sample itself has a large deformation. Moreover, the strain range of yield point in the first stage is between $2 \%$ and $7 \%$. After reaching the yield point, stress yield begins to occur. 

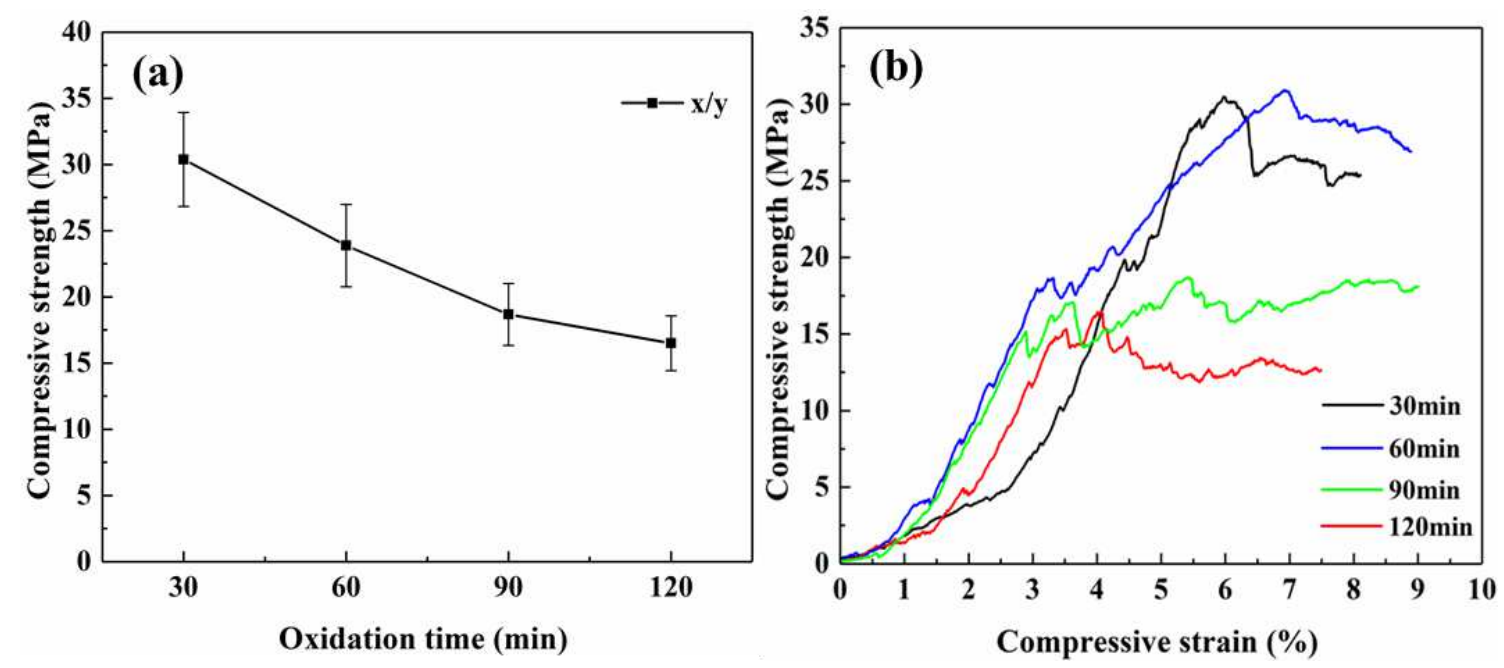

Fig. 16 Compressive strength and compressive strength-strain curves of $\mathrm{C}_{\mathrm{f}} / \mathrm{SiC} / \mathrm{SiHfBOC}$ composites in the $\mathrm{x} / \mathrm{y}$ direction at different oxidation time: (a) compressive strength (b) compressive strength-strain curves

\section{Conclusion}

In this paper, the on-demand preparation of $\mathrm{C}_{\mathrm{f}} / \mathrm{SiC} / \mathrm{SiHfBOC}$ composites is realized, to control the microstructure and properties of the composites. When the PIP cycle times increased from 3 to 7 , the density and porosity of the composites increased from $1.02 \mathrm{~g} / \mathrm{cm}^{3}$ and $52.53 \%$ to $1.40 \mathrm{~g} / \mathrm{cm}^{3}$ and $28.87 \%$, respectively. And the compressive strength in the $\mathrm{x} / \mathrm{y}$ and $\mathrm{z}$ directions increased from 31.32 \pm 6.12 $\mathrm{MPa}$ and $9.31 \pm 1.23 \mathrm{MPa}$ to $77.56 \pm 8.56 \mathrm{MPa}$ and 40.03 $\pm 5.48 \mathrm{MPa}$, respectively. The strengthening and toughening methods mainly include fiber debonding, fiber pulling out, and fiber breaking. The products of $\mathrm{C}_{\mathrm{f}} / \mathrm{SiC} / \mathrm{SiHfBOC}$ composites after the static oxidation test mainly include $\mathrm{CO}_{2}, \mathrm{CO}, \mathrm{B}_{2} \mathrm{O}_{3}, \mathrm{SiO}_{2}, \mathrm{HfSiO}_{4}$, etc. According to the analysis of compressive stress-strain curve, oxidation weight retention rate, and oxidation surface SEM, it was found that the weight retention and compressive strength of $\mathrm{C}_{\mathrm{f}} / \mathrm{SiC} / \mathrm{SiHfBOC}-7$ sample were $83.97 \%$ and $23.88 \pm 3.11 \mathrm{MPa}$ respectively after being oxidized at $1500{ }^{\circ} \mathrm{C}$ for $60 \mathrm{~min}$, which further proved that the $\mathrm{C}_{\mathrm{f}} / \mathrm{SiC} / \mathrm{SiHfBOC}$ composites could be used in oxidation environment at $1500{ }^{\circ} \mathrm{C}$ for a long time.

\section{Acknowledgments}

This work is supported by Key Program of National Natural Science Foundation of China (No. 52032003), National Natural Science Foundation of China (No. 51972082), National Natural Science Foundation of China (No. 51772061), Science Foundation of the National Key Laboratory of 
Science and Technology on Advanced Composites in Special Environments (No.6142905202112), and Heilongjiang Provincial Postdoctoral Science Foundation (No.LBH-Z20144).

\section{References}

[1] Arai Y, Inoue R, Goto K, Y. Kogo, et al. Carbon fiber reinforced ultra-high temperature ceramic matrix composites: A review. Ceram Int 2019, 45: 14481-14489.

[2] Luan X, Yuan J, Wang J, et al. Laser ablation behavior of $\mathrm{C}_{f} / \mathrm{SiHfBCN}$ ceramic matrix composites. J Eur Ceram Soc 2016, 36: 3761-3768.

[3] Lyu Y, Tang H, Zhao GD, Effect of Hf and B incorporation on the SiOC precursor architecture and high-temperature oxidation behavior of SiHfBOC ceramics. J Eur Ceram Soc 2020, 40: 324-332.

[4] Cheng J, Wang XZ, Wang J, et al. Synthesis of a novel single-source precursor for HfC ceramics and its feasibility for the preparation of Hf-based ceramic fibres. Ceram Int 2018, 44: 7305-7309.

[5] Singh M, Ohji T, Dong S, et al. Advances in High Temperature Ceramic Matrix Composites and Materials for Sustainable Development: Ceramic Transactions Volume 263, B. Legin, Z. Aboura, F. Bouillon, and S. Denneulin. Wiley, 2017: 401-412.

[6] Colombo P, Mera G, Riedel R, et al. Polymer-Derived Ceramics: 40 Years of Research and Innovation in Advanced Ceramics. J Am Ceram Soc 2010, 93: 1805-1837.

[7] Cheng YH, Liu YX, An YM, et al. High thermal-conductivity $\mathrm{rGO} / \mathrm{ZrB}_{2}-\mathrm{SiC}$ ceramics consolidated from $\mathrm{ZrB}_{2}$-SiC particles decorated GO hybrid foam with enhanced thermal shock resistance. J Eur Ceram Soc 2020, 40: 2760-2767. 
[8] Lee SH, Lun F, Chung K. Ultra-high Temperature Ceramics-Ceramic Matrix Composites (UHTC-CMC). Compos Res 2017, 30: 94-101.

[9] Cheng YH, An YM, Liu Y, et al. ZrB2-Based "Brick-and-Mortar" Composites Achieving the Synergy of Superior Damage Tolerance and Ablation Resistance. ACS Appl Mater \& Int 2020, 12: $33246-33255$.

[10] Cheng YH, Lyu Y, Han WB, et al. Multiscale toughening of $\mathrm{ZrB}_{2}-\mathrm{SiC}-$ Graphene@ $\mathrm{ZrB}_{2}-\mathrm{SiC}$ dual composite ceramics. J Am Ceram Soc 2019, 102: 2041-2052.

[11] Zhang XH, Liu C, Hong CQ, et al. Sol-gel-derived SiBOC ceramics with highly graphitized free carbon. Ceram Int 2015, 41: 15292-15296.

[12] Papendorf B, Ionescu E, Kleebe HJ, et al. High-Temperature Creep Behavior of Dense SiOCBased Ceramic Nanocomposites: Microstructural and Phase Composition Effects. J Am Ceram Soc 2013, 96: 272-280.

[13] Harshe R, Balan C, Riedel R. Amorphous Si(Al)OC ceramic from polysiloxanes: bulk ceramic processing, crystallization behavior and applications. J Eur Ceram Soc 2004, 24: 3471-3482.

[14] Miao Y, Yang ZH, Zhu QS, et al. Thermal ablation behavior of SiBCN-Zr composites prepared by reactive spark plasma sintering. Ceram Int 2017, 43: 7978-7983.

[15] Yuan J, Luan X, Riedel R, et al. Preparation and hydrothermal corrosion behavior of $\mathrm{C}_{f} / \mathrm{SiCN}$ and $\mathrm{C}_{f} / \mathrm{SiHfBCN}$ ceramic matrix composites. J Eur Ceram Soc 2015, 35: 3329-3337.

[16] Siqueira RL, Yoshida IVP, Pardini LC, et al. Poly(borosiloxanes) as precursors for carbon fiber ceramic matrix composites. Mater Res 2007, 10: 147-151. 
[17] Rubio V, Ramanujam P, Cousinet S, et al. Thermal properties and performance of carbon fiberbased ultra-high temperature ceramic matrix composites ( $C_{f}$-UHTCMCs). J Am Ceram Soc 2020, 103: 3788-3796.

[18] Yan CL, Liu RJ, Zhang CR, et al. Effects of SiC/HfC ratios on the ablation and mechanical properties of 3D C $/$ HfC-SiC composites. J Eur Ceram Soc 2017, 37: 2343-2351.

[19] Binner J, Porter M, Baker B, et al. Selection, processing, properties and applications of ultrahigh temperature ceramic matrix composites, UHTCMCs-a review. Int Mater Rev. 2019, 19: $389-444$.

[20] Asl MS, Nayebi B, Ahmadi Z, et al. Effects of carbon additives on the properties of $\mathrm{ZrB}_{2}$-based composites: A review. Ceram Int 2018, 44: 7334-7348.

[21] Song J, Han W, Dong S, et al. Constructing hydrothermal carbonization coatings on carbon fibers with controllable thickness for achieving tunable sorption of dyes and oils via a simple heat-treated route. J Coll \& Int Sci 2020, 559: 263-272.

[22] Carminati P, Jacques S, Rebillat F, Oxidation/corrosion of BN-based coatings as prospective interphases for SiC/SiC composites. J Eur Ceram Soc 2020, 41:3120-3131.

[23] Chen ZK, Wang LJ, Wang HR, et al. Effect of microstructure on impact resistance of chemical vapor deposited SiC coating on graphite substrate, Surf Coat Tech 2019, 380: 125076.

[24] Bao YW, Cao ZC, Ma JR, et al. Fine ceramics (advanced ceramics, advanced technical ceramics)-Test method for flexural strength of monolithic ceramics at room temperature. GB/T 6569-2006 National Library of Standards, 2006. 
[25] Tavakoli AH, Campostrini R, Gervais C, et al. Energetics and Structure of Polymer-Derived Si(B-)O-C Glasses: Effect of the Boron Content and Pyrolysis Temperature. J Am Ceram Soc 2014, 97: 303-309.

[26] Jothi S, Ravindran S, Neelakantan L, et al. Corrosion behavior of polymer-derived SiHfCN(O) ceramics in salt and acid environments. Ceram Int 2015, 41: 10659-10669.

[27] Kleebe HJ, Nonnenmacher K, Ionescu E, et al. Decomposition-Coarsening Model of $\mathrm{SiOC} / \mathrm{HfO}_{2}$ Ceramic Nanocomposites Upon Isothermal Anneal at $1300{ }^{\circ} \mathrm{C}$. J Am Ceram Soc 2012, 95: 2290-2297.

[28] Yuan J, Galetz M, Luan XG, et al. High-temperature oxidation behavior of polymer-derived SiHfBCN ceramic nanocomposites. J Eur Ceram Soc 2016, 36: 3021-3028.

[29] Kaur S, Mera G, Riedel R, et al. Effect of boron incorporation on the phase composition and high-temperature behavior of polymer-derived silicon carbide. J Eur Ceram Soc 2016, 36: 967977.

[30] Liao NB, Xue W, Zhou HM, et al. Molecular dynamics investigation of structure and hightemperature mechanical properties of SiBCO ceramics. J Alloy Compd 2014, 610: 45-49.

[31] Schiavon MA, Armelin NA, Yoshida IVP, Novel poly(borosiloxane) precursors to amorphous SiBCO ceramics. Mater Chem Phys 2008, 112: 1047-1054.

[32] Yuan J, Hapis S, Breitzke H, et al. Single-source-precursor synthesis of hafnium-containing ultrahigh-temperature ceramic nanocomposites (UHTC-NCs). Inor Chem 2014, 53: 1044310455. 
[33] Yuan J, Li D, Johanns KE, et al. Preparation of dense SiHf(B)CN-based ceramic nanocomposites via rapid spark plasma sintering. J Eur Ceram Soc 2017, 37: 5157-5165.

[34] Ionescu E, Kleebe HJ, Riedel R. Silicon-containing polymer-derived ceramic nanocomposites (PDC-NCs): preparative approaches and properties. Chem Soc Rev 2012, 41: 5032-5052.

[35] Wu ML, Ren CZ. Active Control of the Anisotropic Wettability of the Carbon Fiber Reinforced Carbon and Silicon Carbide Dual Matrix Composites (C/C-SiC). Appl Surf Sci 2015, 327: 424431.

Open Access This article is licensed under a Creative Commons Attribution 4.0 International License, which permits use, sharing, adaptation, distribution and reproduction in any medium or format, as long as you give appropriate credit to the original author(s) and the source, provide a link to the Creative Commons licence, and indicate if changes were made. The images or other third-party material in this article are included in the article's Creative Commons licence, unless indicated otherwise in a credit line to the material. If material is not included in the article's Creative Commons licence and your intended use is not permitted by statutory regulation or exceeds the permitted use, you will need to obtain permission directly from the copyright holder.

To view a copy of this licence, visit http://creativecommons. org/licenses/by/4.0/. 
Figures

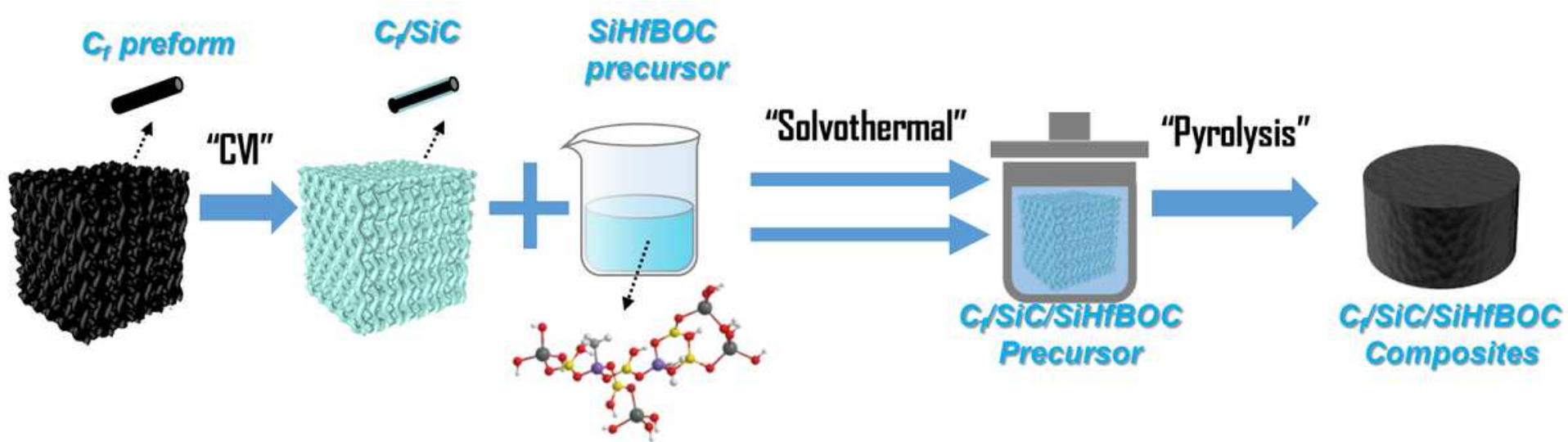

\section{Figure 1}

Illustration of the preparation process of $\mathrm{Cf} / \mathrm{SiC} / \mathrm{SiHfBOC}$ composites.

\section{Figure 2}

(a) XRD pattern of Cf preform and SiC coating coated Cf preform; (b)-(d) SEM of Cf preform and SiC coating coated $\mathrm{Cf}$ preform at different magnification: 

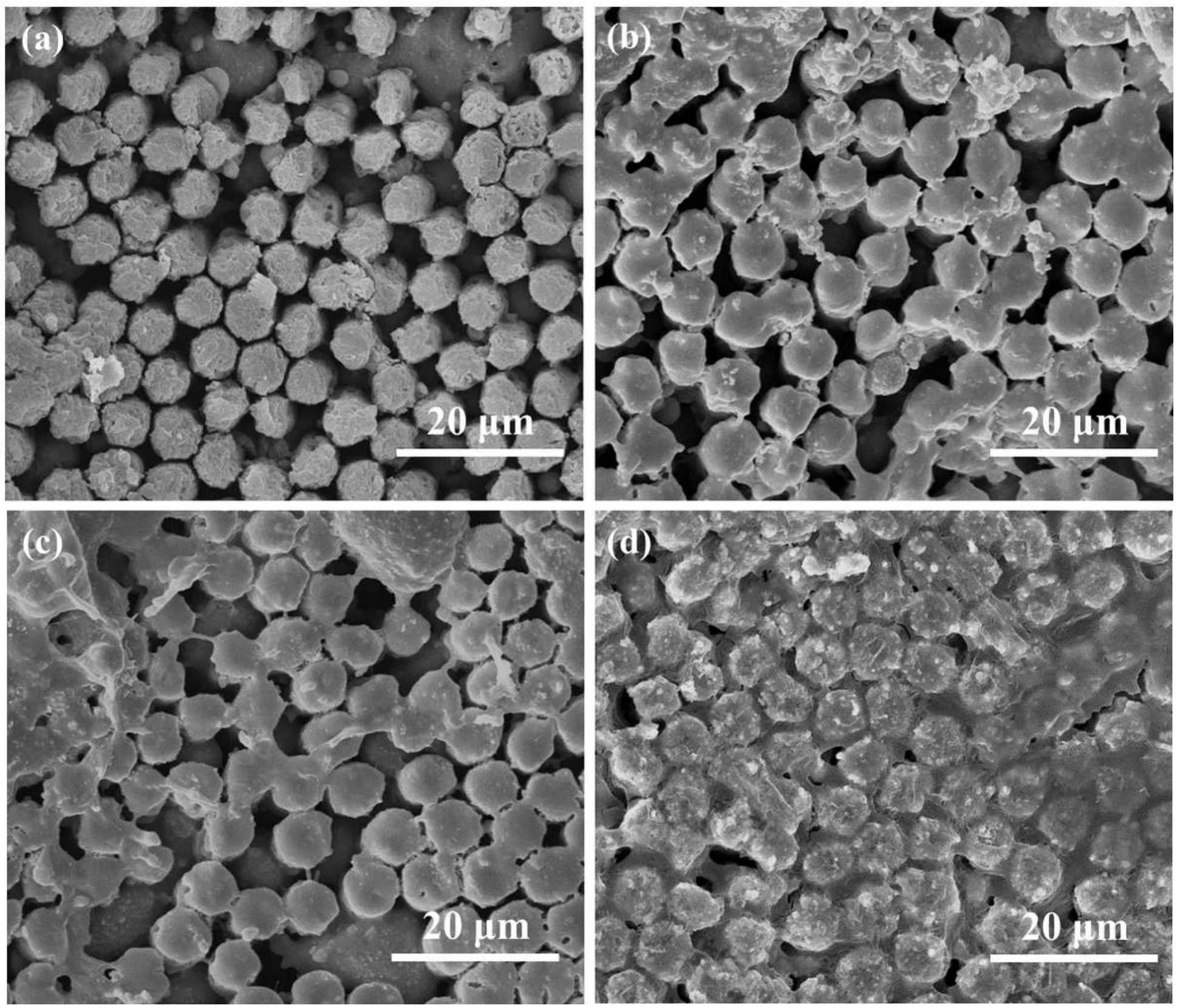

Figure 3

SEM of Cf/SiC/SiHfBOC composites after different PIP cycle times: (a) 4 PIP cycle times, (b) 5 PIP cycle times, (c) 6 PIP cycle times, (d)7 PIP cycle times

Figure 4

XRD pattern of $\mathrm{Cf} / \mathrm{SiC} / \mathrm{SiHfBOC}-7$ composites before and after oxidation

Figure 5 
SEM images and weight retention ratio of $\mathrm{Cf} / \mathrm{SiC} / \mathrm{SiHfBOC}$ composites with different densities oxidized at 1100 for 10 min: (a) 4 PIP cycle times, (b) 5 PIP cycle times, (c) 6 PIP cycle times, (d), (e) 7 PIP cycle times, (f) weight retention ratio

\section{Figure 6}

SEM images and EDS diagram of composite materials after oxidation at $1100 \otimes$ for $10 \mathrm{~min}$

\section{Figure 7}

SEM images of $\mathrm{Cf} / \mathrm{SiC} / \mathrm{SiHfBOC}$ composites after $10 \mathrm{~min}$ of oxidation at different oxidation temperatures: $(a, e) 1200 \rrbracket,(b, f) 1300 \rrbracket,(e, g) 1400 \rrbracket,(d, h) 1500 \rrbracket$

\section{Figure 8}

XRD pattern and weight retention ratio of $\mathrm{Cf} / \mathrm{SiC} / \mathrm{SiHfBOC}$ composites after 10 min oxidation at different oxida-tion temperatures:(a) XRD pattern, (b) weight retention ratio

\section{Figure 9}

SEM images of Cf/SiC/SiHfBOC composites after different oxidation time at 1500 : $(a, e) 30$ min, (b, f) $60 \mathrm{~min},(\mathrm{c}, \mathrm{g}) 90 \mathrm{~min},(\mathrm{~d}, \mathrm{~h}) 120 \mathrm{~min}$

\section{Figure 10}

XRD pattern and weight retention ratio of $\mathrm{Cf} / \mathrm{SiC} / \mathrm{SiHfBOC}$ composites after oxidation at $1500 \otimes$ with different oxidation time: (a) XRD pattern, (b) weight retention ratio

\section{Figure 11}

Compressive strength of $\mathrm{Cf} / \mathrm{SiC} / \mathrm{SiHfBOC}$ composites with different densities

\section{Figure 12}

Compressive strength-strain curves of $\mathrm{Cf} / \mathrm{SiC} / \mathrm{SiHfBOC}$ composites with different PIP cycle times: (a) x/y direction (b) z direction 


\section{Figure 13}

Flexural strength and flexural strength-displacement curves of $\mathrm{Cf} / \mathrm{SiC} / \mathrm{SiHfBOC}$ composites with different PIP cycle times in the $x / y$ direction and $z$ direction: (a) flexural strength, (b) flexural strength-displacement curves
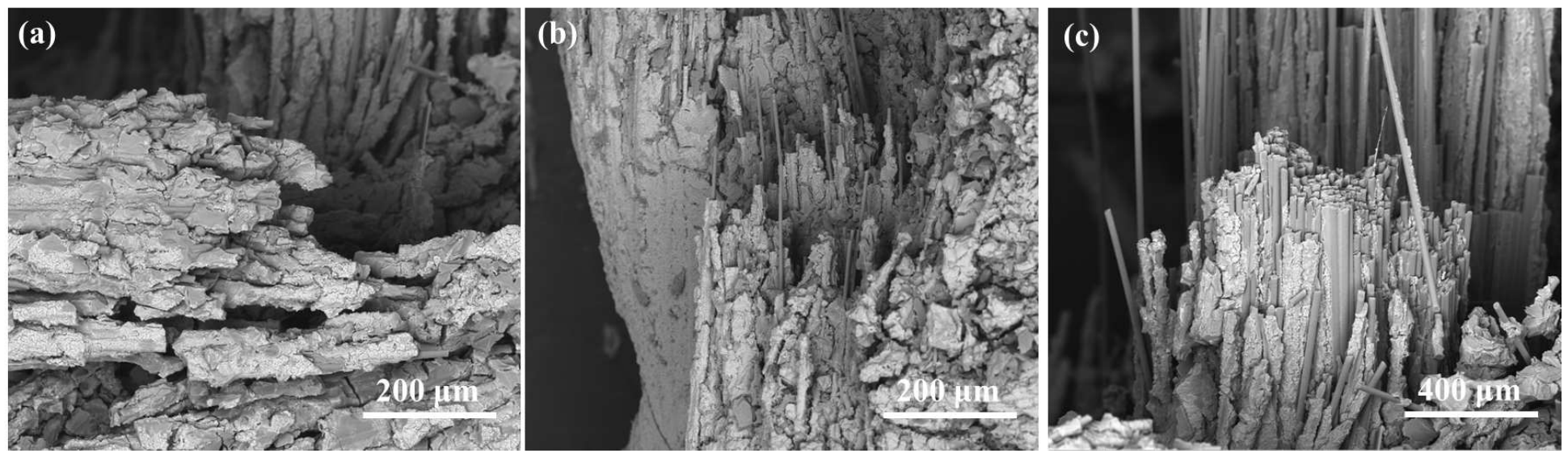

\section{Figure 14}

Fracture morphology of $\mathrm{Cf} / \mathrm{SiC} / \mathrm{SiHfBOC}$ composites: (a) fiber debonding, (b) fiber pulling out, (c) fiber fracture

\section{Figure 15}

Compression strength and compressive strength-strain curves of $\mathrm{Cf} / \mathrm{SiC} / \mathrm{SiHfBOC}$ composites in the $\mathrm{x} / \mathrm{y}$ direction at different oxidation temperatures: (a) compression strength, (b) compressive strength-strain curves

\section{Figure 16}

Compressive strength and compressive strength-strain curves of $\mathrm{Cf} / \mathrm{SiC} / \mathrm{SiHfBOC}$ composites in the $\mathrm{x} / \mathrm{y}$ direction at different oxidation time: (a) compressive strength (b) compressive strength-strain curves

\section{Supplementary Files}

This is a list of supplementary files associated with this preprint. Click to download.

- Supplementary.docx 